\title{
Scale of attentional focus in visual search
}

\author{
P. M. GREENWOOD and RAIA PARASURAMAN \\ Catholic University of America, Washington, D.C.
}

\begin{abstract}
The effects of the spatial scale of attention on feature and conjunction search were examined in two experiments. Adult participants in three age groups-young, young-old, and old-old-were given precues of varying validity and precision in indicating the location of a target letter subsequently presented in a visual array. Systematic decreases in the size of a valid precue (toward the size of the target) progressively facilitated both feature and conjunction search, with a greater benefit accruing to conjunction search. Age-related slowing in conjunction search was mitigated by precise (small and valid) precues, presumably because they reduced the need for participants in the young-old group to focus and to shift attention. Nevertheless, this benefit was reduced in the old-old group. The effects of valid location precue size varied with cue-target stimulus onset asynchrony (SOA) in a manner that interacted with search difficulty: Effects of cue size developed more rapidly in feature search but more slowly in conjunction search. Finally, when precues were invalid for target location, search was faster with larger sized precues. Thus, in both easy feature search and hard conjunction search, the scale of visuospatial attention modulates the speed of visual search. Furthermore, when the SOA is sufficiently long for cue effects to develop, the ability to dynamically adjust the scale of visuospatial attention appears to decline in advanced age. These results go beyond current models in suggesting that visuospatial attention possesses two dynamic properties - shifting in space and varying in scale-that are deployed independently, depending on task demands.
\end{abstract}

The problem of searching for and detecting anticipated events in a visually rich environment is a complex one, requiring heightened sensitivity of the sensory and perceptual systems to those portions of space in which objects are expected to appear. Typically, individuals make overt head and saccadic eye movements in order to search for target events among distractors. However, saccadic latencies (200-250 msec) are not sufficiently rapid to account for spatial selection between objects that can occur as fast as 30-40 msec/object. Consequently, a covert spatial attention mechanism that is operative within a single fixation has been postulated as a requirement for visual search tasks (Koch \& Ullman, 1985; Treisman, 1996; Treisman \& Gelade, 1980).

Covert attention has typically been studied by using location-cuing tasks in which observers are provided with cues that predict the subsequent location of a target presented in isolation (Posner, 1980). Observers are fastef to detect the target when the cue correctly indicates the target location (valid cue) than when it does not (invalid cue). Sensory processing of the target appears to be facilitated

\footnotetext{
A preliminary report of these data was presented at the 1992 Society for Neuroscience meeting. This research was supported by an Alzheimer's Association/Ana M. Buchanan Memorial InvestigatorInitiated Research Grant and Research Grant AG12387 from the National Institute on Aging to P.M.G. and by Research Grant AG07569 from the National Institute on Aging to R.P. Correspondence concerning this article should be addressed to P. M. Greenwoood, Cognitive Science Laboratory, Psychology Department, Catholic University of America, Washington, DC 20064 (e-mail: greenwood@cua.edu).
}

as a consequence of the shift of spatial attention to the cued location (Hawkins et al., 1990). The consequent decrease (benefit) in reaction time (RT) is presumed to reflect the engagement of attentional focus at the target location. The increase (cost) in RT following an invalid cue is thought to reflect the disengagement and shifting of spatial attention away from the incorrect to the correct target location (Posner, 1980).

In location-cuing tasks, participants have to attend to a target presented alone in an otherwise empty visual field. This is a rare occurrence in most real-world visual tasks, in which observers typically have to detect targets presented among distractors in a complex visual field. However, there is evidence from both cognitive (Briand \& Klein, 1987; Parasuraman, Greenwood, \& Alexander, 1995; Prinzmetal, Presti, \& Posner, 1986) and functional brain-imaging (Corbetta, Shulman, Miezin, \& Petersen, 1995) studies that the covert spatial attention mechanism postulated in location-cuing tasks is also operative in visual search tasks (see, also, Treisman, 1996).

Not all search tasks may require the use of the covert spatial attention mechanism. A number of models that predict when search is attention sensitive and when it is not have been proposed, beginning with Treisman's influential feature integration theory (FIT; Treisman, 1988; Treisman $\&$ Gelade, 1980). When the target differs from the distractors by a unique feature, producing the subjective phenomenon of popout, the number of distractors in the array has no effect on the time to detect the target (Julesz \& Bergen, 1983; Treisman, 1985). FIT claims that visual features are encoded through preattentive analyses performed in parallel over the visual field. In contrast, when 
the target is defined by a conjunction of two features or is hard to discriminate from the distractors, the time to detect the target increases linearly with the number of distractors. Treisman interprets this result as reflecting serial deployment of visuospatial attention to each item.

Wolfe and colleagues (Cave \& Wolfe, 1990) proposed a modified version of FIT, guided search theory (GST). This theory attempts to account for evidence that fast, apparently parallel search is possible even when the target is defined by a conjunction of features (Nakayama \& Silverman, 1986). According to GST, all the primitive features are processed by searching a subset of the field by means of interaction between parallel and serial stages. The item with the greatest amount of activation in the map created by the parallel stage is selected as the target by the serial stage. On this view, preattentive feature information is used in the serial stage to guide visuospatial attention to those stimuli possessing the designated features. In Treisman's more recent version of her theory (Treisman, 1988) and in Julesz's texton theory (Julesz, 1984), spatial attention is required even in popout situations, with the popout item calling attention to its location.

Finally, Duncan and colleagues (Desimone \& Duncan, 1995; Duncan \& Humphreys, 1989) have rejected the spotlight view of visual attention inherent in both FIT and GST, postulating rather that attention emerges from mechanisms aimed at resolving competition by perceived objects for limited visual processing resources. These mechanisms are biased toward objects by spatial location or by features or conjunctions of features, so that search is viewed as always parallel, although a top-down component is incorporated into a later version of the model (Desimone \& Duncan, 1995). These theoretical accounts differ fundamentally in the mechanisms of search, with Treisman claiming that search can be conducted by either parallel or serial mechanisms and Duncan claiming that search is only parallel but is capable of being biased in a top-down manner (Duncan, Humphreys, \& Ward, 1997).

Thus, visual search models differ with respect to the conditions under which search is attention sensitive. When search is dependent on attention, however, a fundamental issue arises that has not been extensively researched to date: Given that observers must attend to and search a particular area of visual space, how does search efficiency vary with the size of the space and with the extent of the participant's attentional focus? Recent work suggests that approximately $7^{\circ}-8^{\circ}$ of visual angle can be searched effectively in one fixation (Previc \& Blume, 1993). Moreover, search efficiency may depend on the ability to make flexible adjustments in the size or scale of attentional focus within this area-attention may be distributed broadly or narrowly (LaBerge \& Brown, 1989). Young adults appear able to adjust the functional size of the attentional focus, as with a zoom lens, in both detection (Castiello \& Umiltà, 1990) and letter discrimination tasks (Eriksen \& Yeh, 1985).

In order to manipulate the scale of the attentional focus in the context of shifts of visuospatial attention, we devel- oped a novel visual search task that combines the locationcuing and standard visual search paradigms (Greenwood, Parasuraman, \& Alexander, 1997). Location precues that varied in size and, hence, in precision were used to examine the influence on search efficiency of dynamic changes in the scale of the attentional focus. There have been a few studies using spatial precues, but these either did not vary precue size (Prinzmetal et al., 1986) or varied it in the absence of the requirement to search (Eriksen \& St. James, 1986). McCalley, Bouwhuis, and Juola (1995) did vary precue size in a search task and found that the ability to confine the attentional focus to the cued area declined as precues became more eccentric. However, this procedure confounds precue eccentricity with precue size, because of the use of ring-shaped cues.

The effects of the spatial scale of attention on performance of visual search tasks have, thus, not been extensively examined. Nor have such effects been examined in both young and older adults. The present study was concerned with both these issues.

\section{Effects of Adult Aging on \\ Spatial Attention and Visual Search}

As people age, the need to identify anticipated events in visual space does not lessen, although the ability to do so may decline. Both overt and covert forms of attentional search appear to be affected by adult aging (Carter, Obler, Woodward, \& Albert, 1983; Plude \& Doussard-Roosevelt, 1989). In studies using the location-cuing paradigm in which a target appearing alone requires only a simple detection response, age has little effect on either RT costs or RT benefits (Greenwood, Parasuraman, \& Haxby, 1993; Hartley, Kieley, \& Slabach, 1990; Nissen \& Corkin, 1985; Robinson \& Kertzman, 1990). Cuing effects in detection tasks are also normal even in the old-old, those over 75 years of age (Greenwood \& Parasuraman, 1994), and in patients with dementia of the Alzheimer type (DAT; Parasuraman, Greenwood, Haxby, \& Grady, 1992). When target discrimination is required, effects of age emerge, but not under all cuing conditions. Central, but not peripheral, cues are associated with increased RT costs and benefits of cue validity for older adults aged up to 75 years, as compared with young adults (Greenwood, Parasuraman, \& Haxby, 1993; Hartley et al., 1990). Ten more years of aging appears to selectively increase the costs of invalid cues, resulting in slower attentional disengagement by the old-old ( $75-85$ years of age), as compared with the youngold (65-74 years; Greenwood \& Parasuraman, 1994). In contrast, age does not differentially slow the RT benefit of a valid cue. Selectively slowed disengagement of spatial attention has also been observed in patients with parietal cortex lesions (Posner, Walker, Friderich, \& Rafal, 1984) and in early, mild DAT patients (Oken, Kishiyama, Kaye, \& Howieson, 1994; Parasuraman et al., 1992). Thus, whereas the ability to engage attention at validly cued locations in a nonsearch task is unaffected by aging, the redirection of attention when the cue is not valid is slowed in advanced aging (Greenwood \& Parasuraman, 1994). 
Age effects have also been studied in visual search. Aging does not alter the apparently parallel nature of feature search (Oken, Kishiyama, \& Kaye, 1994; Plude \& Doussard-Roosevelt, 1989). Aging does alter conjunction search by increasing the effect of the number of distractors on search RT - that is, by increasing the slope of the RT/distractor number function (Plude \& DoussardRoosevelt, 1989). This result has been replicated (Foster, Behrmann, \& Stuss, 1995) and extended to conjunctions of form and movement (Kramer, Martin-Emerson, Larish, \& Andersen, 1996). Several studies have also reported that search slopes for accuracy were steeper in older than in younger participants (Harpur, Scialfa, \& Thomas, 1995; Kramer, Martin-Emerson, Larish, \& Anderson, 1996; Oken, Kishiyama, et al., 1994). Nevertheless, the elderly appear to use a strategy in serial search that is similar to that of the young. When the number of distractors possessing one feature of the target was held constant, the old were as able as the young to confine search to items possessing only the relevant feature (Plude \& DoussardRoosevelt, 1989). This was interpreted as indicating that although young and old participants differed in search speed, they did not differ in search strategy.

Taken as a whole, these studies suggest that healthy adult aging may alter components of visuospatial attention selectively. From nonsearch tasks, it can be concluded that the ability to deploy attention at a spatial location is unaltered by aging, whereas the ability to dynamically redirect visual attention following an invalid cue is slowed (Greenwood \& Parasuraman, 1994; Hartley, Kieley, \& McKenzie, 1992). One possibility, therefore, is that agerelated slowing in conjunction search can be attributed to slowness in repeatedly engaging and disengaging attention during the shifts from item to item required in conjunction search.

The efficiency of such repeated shifts of spatial attention might depend, at least partially, on the ability to make flexible adjustments in the size or scale of the attentional focus. The functional size of the attentional focus can be adjusted in normal young participants (Castiello \& Umiltà, 1990; Eriksen \& Yeh, 1985). Older adults under age 75 have been found to be similar to the young in their ability to use either a broad or a narrow focus of attention, when searching for targets in circular (Madden, 1992; Madden, Connelly, \& Pierce, 1994) or in horizontal (Hartley et al., 1992) arrays. If, during a search task, an observer narrows the attentional focus to match the size of the target, any factor that slows such adjustment could also retard search speed. Therefore, a decline with age in the ability to scale the attentional focus to an optimal size for search might underlie the age-related slowing seen during conjunction search (Plude \& Doussard-Roosevelt, 1989).

To investigate this question, we employed size and location precues in a visual search task to determine the effect of the size or the scale of the attentional focus on the speed and accuracy of visual search. Treisman's (1988) view that any factor affecting visuospatial attention should alter conjunction search more than it does feature search is supported by the finding of Prinzmetal et al. (1986) that spatially precuing a quadrant containing the target increased the accuracy of conjunction, but not of feature, detection. We reasoned that varying the precision of the location cue by varying its size would further alter search efficiency. The specific assumption to be tested is that varying the size of a location precue manipulates the size of the attentional focus. We predicted that decreases in the size of a valid location precue toward the size of the target would progressively facilitate conjunction search, but not feature search, which is postulated to benefit from a larger attentional focus.

Different predictions were made for performance with invalid location cues. A narrow attentional focus at the incorrect location was predicted to impede parallel feature search. Therefore, we predicted that when the precue is invalid, feature search, claimed to depend on parallel search, would be facilitated by a larger attentional focus. On invalidly cued conjunction search trials, inducing an element-sized attentional focus by a small precue would eliminate the need to adjust the size of the focus, leaving only the need to shift the focus in order to search. This condition would be predicted to speed search, as compared with trials with a larger precue, following which the focus would need to be both adjusted and shifted for efficient search.

Predictions concerning effects of aging on the ability to dynamically adjust the attentional focus derive from evidence of age-related slowing in conjunction search (Foster et al., 1995; Plude \& Doussard-Roosevelt, 1989). If such slowing is due to impairment in the ability to shift the focus of visuospatial attention, but not in the ability to adjust the scale of the focus, effects of the validity, but not of the size, of location cues would be related to aging. If only the ability to shift the attentional focus is affected by aging, it can be predicted that such effects would be mitigated by variations in the precision of location precues inducing changes in the scale of the attentional focus, so that increased cue precision could reduce the participants' need both to focus and to shift attention. The result would be an elimination of age effects in conjunction search by the appearance of precise and valid precues before the search array. Alternatively, the slowing of conjunction search by aging could arise from problems in adjusting the scale of the attentional focus. If so, a larger precue could slow search more than a smaller precue would. From such a result, it could be argued that one source of the observed age-related slowing on conjunction search speed without precues (Plude \& DoussardRoosevelt, 1989) is a reduced ability to adjust the scale, as well as the location, of the attentional focus.

In what follows, as in the above, we use the terms feature and conjunction search, while acknowledging that search difficulty-easy and hard search, as described by Duncan and Humphreys (1989) — may be more predic- 
Table 1

Means and Standard Errors of Demographic Characteristics of Participant Groups in Experiment 1

\begin{tabular}{|c|c|c|c|c|c|c|}
\hline & \multicolumn{2}{|c|}{ Young } & \multicolumn{2}{|c|}{ Young-Old } & \multicolumn{2}{|c|}{ Old-Old } \\
\hline & $M$ & $S E$ & $M$ & $S E$ & $M$ & $S E$ \\
\hline Number & 18 & & 18 & & 18 & \\
\hline Female/Male & $7 / 11$ & & $12 / 6$ & & $7 / 11$ & \\
\hline Age (years) & 19.4 & 0.49 & 68.2 & 0.79 & 78.0 & 0.49 \\
\hline Education (years) & 12.8 & 0.32 & 17.0 & 0.49 & 15.9 & 0.61 \\
\hline \multicolumn{7}{|c|}{ Logical memory (WMS) } \\
\hline Immediate & 13.1 & 0.54 & 15.2 & 0.69 & 11.3 & 0.80 \\
\hline Delayed & 11.0 & 0.74 & 14.2 & 0.72 & 10.6 & 0.82 \\
\hline
\end{tabular}

tive of search efficiency than the qualitative category of search.

\section{EXPERIMENT 1}

\section{Method}

\section{Participants}

The young group was composed of 18 undergraduates, $18-25$ years of age, who participated to fulfill a requirement for an introductory psychology course. Thirty-six older volunteers were also recruited by newspaper advertisement and were paid for their participation. They were divided by age into two groups of 18 participants each, a young-old group (63-74 years) and an old-old group (76-84 years). Mean ages, years of education, and Wechsler Memory Scale (WMS) Logical Memory scores (Wechsler, 1981) are reported in Table 1. Both immediate and delayed WMS scores differed significantly between age groups [WMS immediate, $F(2,51)=8.01$, $p<.001$; WMS delayed, $F(2,51)=6.53, p<.01$ ]. For both immediate and delayed scores, a post hoc analysis showed that the youngold differed significantly both from the young and from the old-old $(p<.05)$. In contrast, the young and old-old groups did not differ. ${ }^{1}$

\section{Stimuli}

This location-cued visual search task employed a precue to indicate, with variable validity and precision, the location of a target letter in an array of letters. Arrays were composed of 10 or 15 letters, arranged in two (array size, $10 ; 7.0^{\circ} \times 2.9^{\circ}$ ) or three (array size, 15; $7.0^{\circ} \times 4.9^{\circ}$ ) rows of 5 letters each (Figure 1). Viewing distance was $60 \mathrm{~cm}$. Letters were T, N, or G, drawn in one of three colors (green, blue, or pink). The target letter was a pink T, present on $50 \%$ of the trials. The order and position of the letters in the arrays were chosen randomly. The inner edge of each array appeared to the left or the right of the fixation by $3.8^{\circ}$.

The location precue was a rectangle varying in size. The smallest (element-sized) precue surrounded one letter (area $=2 \mathrm{~cm}^{2}, 1.7^{\circ}$ $\times 1.3^{\circ}$ ); the next larger precue surrounded one column of letters (column-sized precue, either $3.8 \mathrm{~cm}^{2}, 1.33^{\circ} \times 3.6^{\circ}$, or $6.6 \mathrm{~cm}^{2}$, $1.33^{\circ} \times 5.5^{\circ}$, depending on array size); and the largest precue surrounded the entire array of letters (array-sized precue, area $=$ $37.6 \mathrm{~cm}^{2}, 7.7^{\circ} \times 5.5^{\circ}$ ).

\section{Procedures}

Following a fixation point (1-sec duration), the screen was erased, and the location precue appeared for $500 \mathrm{msec}$ before the array of letters was presented. The location precue then remained on the screen, superimposed over the array, until the participant responded or $2 \mathrm{sec}$ elapsed. Therefore, depending on the size of the cue, either one letter, one column of letters, or all letters appeared inside the location precue. The use of a $500-\mathrm{msec}$ precue stimulus onset asynchrony (SOA) was based on previous work showing that the ef- fects of central, symbolic location cues develop later than the effects of peripheral cues (Greenwood \& Parasuraman, 1994; Müller \& Findlay, 1988). Also, the effects of central cue validity develop later in a discrimination task than in a detection task (Greenwood et al., 1993). Although the cues employed in the present study certainly appeared peripherally, in a nonsearch task effects of precue size are evident $500 \mathrm{msec}$, but not $40 \mathrm{msec}$, after cue onset (Castiello \& Umiltà, 1990). Peripheral cue validity effects have been observed in a four-item search task with an SOA as long as $750 \mathrm{msec}$ (Müller \& Findlay, 1987). Therefore, in the absence of prior knowledge about the time course of precue effects with a large, complex array, it was deemed safest to use a long SOA.

The participants were required to make a speeded decision about the presence or absence of the target letter (a pink T). The task was presented in six blocks, each of which lasted about 10 min and contained a randomly selected mixture of all the experimental conditions. The experimental conditions were target presence, array size $(10,15)$, cue size (one letter, one column of letters, the entire array), and task type (feature, conjunction, combined). Task type is defined below.

Cue conditions. Cues were valid on $80 \%$ and invalid on $20 \%$ of the trials. Trials could not be valid when the target was absent. On invalid trials, although the two smaller cue sizes indicated array locations that did not contain the target, the largest cue could only be invalid by indicating a location away from the array and was, therefore, centered in the half of the screen opposite to that containing the array.

Search conditions. Tasks were designed to elicit feature and conjunction search, and a third type combined elements of each. The participants were required to search for the target (pink T) in all three tasks: (1) a search for one feature (color pink), in which only the target possessed target color and form; (2) a search for a conjunction of features, in which the target properties of color (pink)
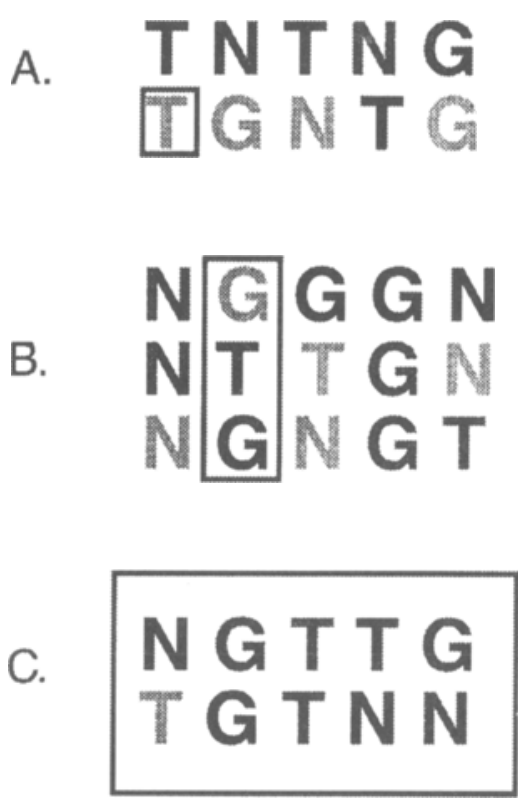

Figure 1. Examples of displays used in Experiment 1, but with shades of gray substituted for color. Light gray represents pink, medium gray represents blue, and black represents green. Panel A: Conjunction search with a valid, element-sized precue in a 10 letter array. Panel B: Conjunction search with an invalid, columnsized precue in a 15-letter array. Panel C: Feature search with a valid, array-sized precue in a 10-letter array. 
and form (letter T) appeared with equal frequency in the array; and (3) a combined search, in which there were only two target color distractors present. Young participants benefit when only a small number of array items possess a property in common with the target (Egeth, Vizri, \& Garbart, 1984). This benefit is thought to arise because participants first select all the items posessing the feature in parallel and then serially search only through those selected items. Although Plude and Doussard-Roosevelt (1989) found no decline in younger elderly participants with such a condition, it was included in the present study, to determine whether a decline in this ability occurs with advanced aging.

\section{Results}

Mean accuracy proportions and median RTs were calculated for each participant for each condition, after excluding RTs less than $100 \mathrm{msec}$. Both dependent measures were subjected to mixed factorial analyses of variance (ANOVAs) in which age was a between-subjects factor and the within-subjects factors were task (feature, conjunction, combined), target presence or absence (PA), cue validity (valid, invalid), cue size ( 1 letter, 1 column of letters, the entire array), and array size ( 10 or 15 letters). Repeated measures $F$ values were corrected for violations from sphericity (Keselman \& Rogan, 1980). For post hoc contrasts of group effects, the Student-Newman-Keuls test was used (Winer, Brown, \& Michels, 1991).

To correct for age group differences in overall speed of responding - that is, to account for generalized cognitive slowing (Cerella, 1990)-RTs were proportionally scaled to overall RT: Median RTs for each participant and each condition were divided by that participant's overall mean RT. Any significant age $\times$ condition interaction in an ANOVA of these proportional scores would then point to effects of condition that differ with age, over and beyond that due to generalized cognitive slowing (see, e.g., Spieler, Balota, \& Faust, 1996). Statistical analyses of the RT data include results from untransformed scores, with results from proportional scores given where they differed from untransformed data. When derived RT measures were used that were relative, such as subtractions or slope values, additional transformation was not performed. In general, transformation did not substantially alter the results, except to eliminate the main effects of age in some, but not all, cases. Therefore, the results from the untransformed data were plotted in the figures.

\section{Accuracy}

In general, accuracy was quite high, ranging from $97.3 \%$ for the old-old group on feature search to $89.4 \%$, again for the old-old group, on conjunction search. The design of this study was not crossed, because trials could not be valid when the target was absent. Therefore, in separate ANOVAs, target-present data were used to test the effects of cue validity, and invalid data were used to test the effects of target PA. There were significant effects for cue validity $[F(1,52)=21.44, p<.0001]$, task $\times$ age group $[F(2,104)=16.57, p<.0001]$, array size $\times$ age group $[F(1,52)=9.66, p<.003]$, and task $X$ array size $\times$ age group $[F(2,104)=12.59, p<.0001]$.

\section{Reaction Times}

To assess the effects of the search task required, an omnibus ANOVA was performed on target-present data. All the main effects were significant: age group $[F(1,52)=$ $74.15, p<.0001]$, task type $[F(2,104)=8.44, p<.001]$, validity $[F(1,52)=100.57, p<.0001]$, array size $[F(1,52)=7.78, p<.0001]$, and cue size $[F(2,104)=$ $48.98, p<.0001]$. There were a number of interactions that survived correction for generalized slowing, but only two that involved age group - task $\times$ cue size $\times$ age group $[F(4,208)=2.81, p<.03]$ and task $\times$ array size $\times$ age group $[F(2,104)=5.02, p<.01]$. The main effect of age group was not sustained. The significant main effect of task type justified a separate analysis of each task, described fully below.

Feature search. For validly cued trials, Figure 2 shows that when the cues were valid and the target was present, there was an overall increase in RT with increases in cue size $[F(2,102)=6.21, p<.01]$ and array size $[F(1,51)=$ $32.15, p<.0001]$, particularly when both the cue and the array were large [array size $\times$ cue size, $F(2,102)=$ $9.81, p<.0001]$. This greater effect of cue size with the larger array increased with age, producing a three-way interaction [array size $\times$ cue size $\times$ age group, $F(2,102)=$ $4.26, p<.003]$. Only the main effect of age $[F(2,51)=$ $27.74, p<.0001]$ was eliminated in the analysis of proportional data.

For invalidly cued trials, considering invalid trials separately allowed analysis of the effect of target PA. The effects of cue size and array size were more orderly when the target was present than when it was absent (Figures $3 \mathrm{~A}$ and $3 \mathrm{~B}$ ). Overall, increasing invalid cue size slowed search RT $[F(2,102)=259.06, p<.0001]$, as did increases in array size $[F(1,51)=104.50, p<.0001]$. These effects of cue size and array size interacted with age group [cue size $\times$ age group, $F(2,102)=7.80, p<$ .0001 ; array size $\times$ age group, $F(2,51)=6.59, p<.003$; array size $\times$ cue size $\times$ age group, $F(2,51)=2.91, p<$ .03]. Target absence reduced effects of age group [PA $X$ age group, $F(2,51)=3.76, p<.03$; PA $\times$ array size $\times$ age group, $F(2,51)=5.70, p<.01]$. Target absence also reduced the effects of cue size [PA $\times$ cue size, $F(2,51)=$ $152.61, p<.0001 ; \mathrm{PA} \times$ array size $\times$ cue size, $F(2,102)=15.56, p<.0001]$ and altered the age effects $[\mathrm{PA} \times$ cue size $\times$ age group, $F(4,102)=30.17, p<$ .0001 ; PA $\times$ array size $\times$ cue size $\times$ age group, $F(4,102)=11.88, p<.0001]$. The only effects that did not retain significance in the corrected data were cue size $\times$ age group and PA $\times$ array size $\times$ age group.

In contrast with the roughly linear increase in search RT when cues were valid, invalid cues exerted a nonlinear effect. When the target was present (Figure 3A) and the array was large, RT was faster to the column-sized cue than to the element-sized cue, but then slowed with the largest cue. When the target was absent (Figure 3B), the results for the smaller cues were less consistent, although again the slowing was greatest with the largest cue in the elderly participants. This slowing with a large, invalid cue may 


\section{FEATURE SEARCH, 500 msec SOA, VALID CUES}

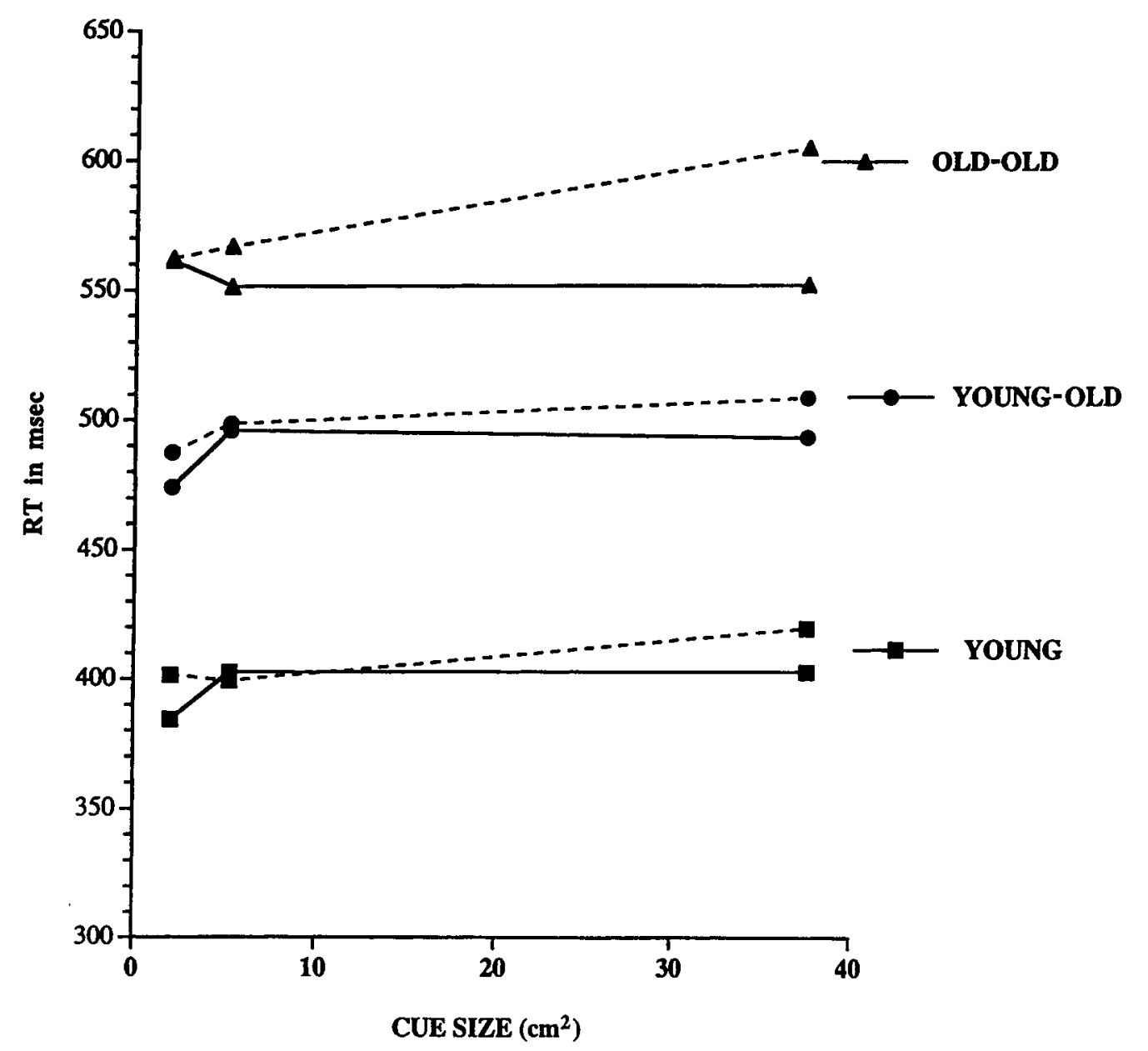

Figure 2. Reaction times (RTs) from validly cued feature search trials in Experiment 1, plotted as a function of cue size for array sizes 10 (solid lines) and 15 (dashed lines) for three age groups, with a 500-msec stimulus onset asynchrony (SOA).

be due to two factors. First, as with valid cues, increased cue size itself may slow target detection by inducing a large attentional focus. Second, since on invalid trials the largest cue appeared on the side of the screen opposite to the array, additional slowing could arise from the need to shift the attentional focus across the screen. If so, our previous findings of slowed disengagement in a cued discrimination task in the old-old group ( 75 years of age or older; Greenwood \& Parasuraman, 1994) would predict that the increase in RT from the middle to the largest cue size would be greatest in the oldest participants. Analysis of these different RTs revealed an overall increase with age group $[F(2,51)=11.11, p<.0001]$. A post hoc test attributed this effect to overall larger difference scores in the old-old group, as compared with both the young-old and the young groups $(p<.05)$. When the target was present, the increase in RT with a column-sized cue (on the same side as the target), as compared with an array-sized cue (opposite the target), was greater in the two elderly groups than in the young group. When the target was absent, these differences were greatest in the old-old group. These effects produced both a PA $\times$ group $[F(2,51)=$ $39.78, p<.0001]$ and a PA $\times$ array size $\times$ group $[F(2,51)=4.37, p<.02]$ interaction.

Examination of Figure $3 \mathrm{~A}$ also shows that, on targetpresent trials when the array was large, the effect of the element-sized invalid cue was to somewhat slow RT, as compared with the middle-sized cue. In order to confirm this, a separate analysis was undertaken. RT slowed with increased array size $[F(1,51)=16.03, p<.0002]$ and with cue size $[F(1,51)=6.31, p<.02]$, and the effect of cue size was greater at the larger array size [array size $\times$ cue size, $F(1,51)=14.02, p<.001]$. Despite the correction for overall differences in RT with age, there was a main 

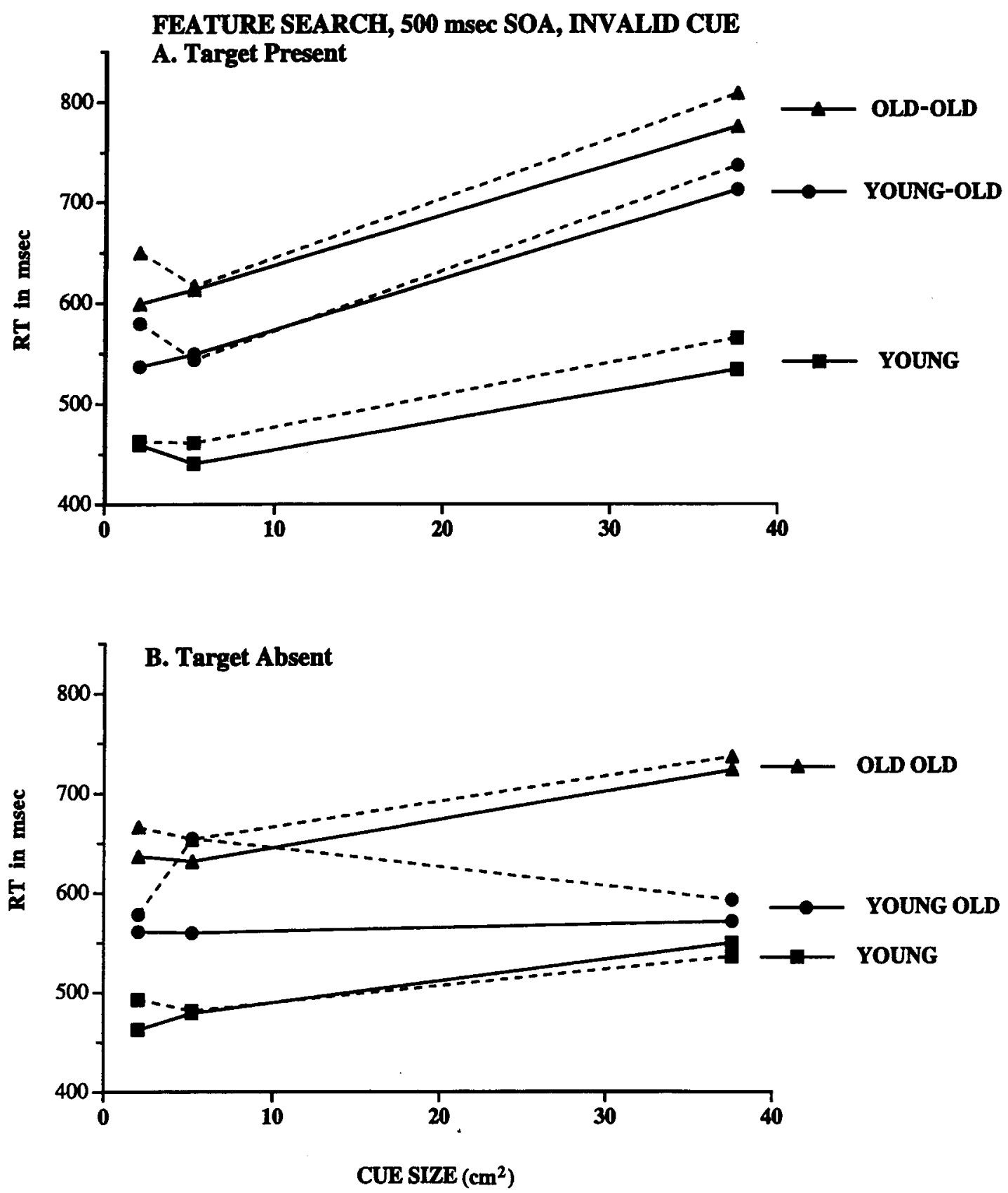

Figure 3. Reaction times (RTs) from invalidly cued feature search trials in Experiment 1, plotted as a function of cue size for array sizes 10 (solid lines) and 15 (dashed lines) and for three age groups, with a 500-msec stimulus onset asynchrony (SOA). Panel A, target present. Panel B, target absent.

effect of age group $[F(2,51)=11.0, p<.0001]$ and a three-way interaction with age [age group $\times$ array size $\times$ cue size, $F(2,51)=10.58, p<.0001]$.

Conjunction search. For validly cued trials, on conjunction search trials, RT was slowed by increased array size $[F(1,51)=125.41, p<.0001]$ and cue size $[F(2,102)=67.53, p<.0001]$. The larger array was associated with a greater effect of cue size [cue size $\times$ array size, $F(2,102)=24.55, p<.0001]$. The age groups differed more at the larger array size [age group $\times$ array size, $F(2,51)=13.56, p<.0001]$. Although the effects of cue size, plotted in Figure 4, appeared to increase from the young to the young-old group and then to decrease again in the old-old group, the interaction of cue size $\times$ age group was only marginally significant $(p<.07)$. There was a main effect of age that was eliminated in the cor- 
CONJUNCTION SEARCH, 500 msec SOA, VALID CUES

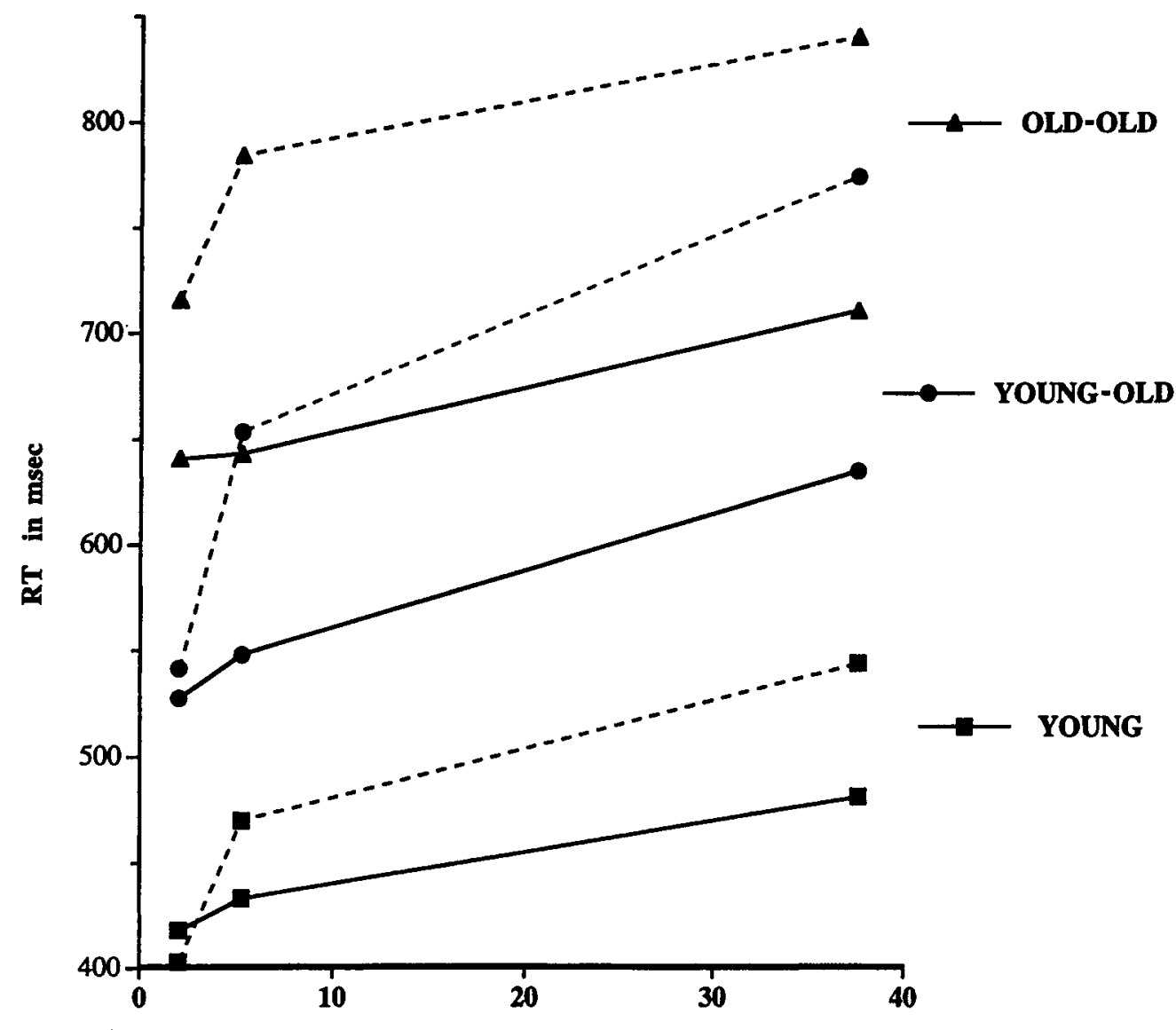

CUE SIZE $\left(\mathrm{cm}^{2}\right)$

Figure 4. Reaction times (RTs) from validly cued conjunction search trials in Experiment 1, plotted as a function of cue size for array sizes 10 (solid lines) and 15 (dashed lines) and for three age groups, with a 500-msec stimulus onset asynchrony (SOA).

rected data. The marginally significant interaction of cue size $\times$ age group remained marginal $(p<.08)$ in the corrected analysis.

Because RT increased approximately linearly with cue size, slopes of the cue-size/RT function were calculated for each participant (Table 2). The slope was steeper for the 15-item than for the 10-item array. Slope values of the valid cue-size/RT functions increased from the young to the young-old group but decreased from the young-old to the old-old group [age group, $F(2,51)=$ $3.34, p<.05]$. When the array was large, slope values were steeper [array size, $F(1,51)=19.54, p<.0001$ ], and the effect of age group on slopes was greater [age group $\times$ array size, $F(2,51)=10.48, p<.04$ ]. To confirm the relation of age to cue-size effects, regressing the valid slopes against age for the two older groups with the larger array produced a significant correlation of -.48 $(p<.003)$.
For invalidly cued trials, RT was slowed by age $[F(2,51)=46.15, p<.0001]$, even when corrected for generalized slowing. RT on invalid trials was also slowed when the target was absent [PA, $F(1,51)=522.21, p<$ $.0001]$ and when the array was larger [array size, $F(1,51)=$ $422.61, p<.0001]$. RT was slowed by increased cue size $[F(4,102)=98.10, p<.0001]$. The effect of cue size was greater when the target was absent $[\mathrm{PA} \times$ cue size, $F(2,102)=4.11, p<.02]$, particularly when the array was large [PA $\times$ array size, $F(2,102)=80.76, p<.0001$ ]. There was also a significant interaction between age group, cue size, and array size $[F(4,102)=2.76, p<.03]$, reflecting the greater effects of both age and cue size when the array was large (Figure 5). These interactions remained significant after adjustment for cognitive slowing.

Invalid cue size did not produce the incremental increase in RT observed on valid trials. On invalid trials when the target was present, RT was faster at the column-sized, as 
Table 2

Reaction Time/Cue-Size Slope Values and Standard Errors for Validly Cued Conjunction Search Trials

\begin{tabular}{|c|c|c|c|c|c|c|}
\hline \multirow[b]{2}{*}{ Array } & \multicolumn{2}{|c|}{ Young } & \multicolumn{2}{|c|}{ Young-Old } & \multicolumn{2}{|c|}{ Old-Old } \\
\hline & $M$ & $S E$ & $M$ & $S E$ & $M$ & $S E$ \\
\hline \multicolumn{7}{|c|}{ Experiment 1} \\
\hline 10 & 1.71 & 0.25 & 2.87 & 0.54 & 2.01 & 0.47 \\
\hline 15 & 3.27 & 0.35 & 5.38 & 1.07 & 2.38 & 0.79 \\
\hline \multicolumn{7}{|c|}{ Experiment 2} \\
\hline 10 & 2.65 & 0.29 & 1.47 & 0.43 & & \\
\hline 15 & 2.94 & 0.57 & 2.20 & 0.77 & & \\
\hline
\end{tabular}

compared with the element-sized cue, but was slowest at the largest cue. As was discussed above, it has been previously observed in nonsearch cued discrimination tasks that RT to invalidly cued targets is slowed in old-old participants (Greenwood \& Parasuraman, 1994). In that study on invalid trials, the side of the screen opposite the target was cued, as was the case in the present visual search task with the largest cue. To determine whether the interactions involving age group, array, and cue size on invalid trials are due to the oldest participants' responding particularly slowly following a large invalid cue, the increase in RT from the middle-sized to the largest cue was calculated and analyzed. On target-present trials, this difference became more pronounced with age, particularly at the larger array [main effect of array size, $F(1,51)=$ $18.35, p<.0001$; interaction of group $\times$ array size, $F(2,51)=6.00, p<.01]$.

Figure 5 shows that when cues were invalid, there was a decrease in RT from the element-sized to the middle-sized cue. RT decreased as cue size increased from small to middle-sized $[F(1,51)=12.72, p<.001]$, and this effect was strongest when the array was large [array size, $F(1,51)=$ $49.29, p<.0001$; cue size $\times$ array size, $F(1,51)=8.63$, $p<.005]$. The main effect of age was not significant when correction for generalized slowing was applied. The absence of significant interactions with age group indicates that the column-sized cue induces an attentional focus that is scaled optimally for both young and old.

To assess the costs plus benefits of cue validity, the total effects of cue validity were assessed by subtracting invalid RT from valid RT, to produce a measure of total costs and benefits. This reflects both the greater benefit derivable from a precisely valid cue and the greater cost from a precise but invalid cue. Because the effect of cue validity at the largest cue probably reflects some combination of disengagement and cue-size effects, this measure was analyzed only at the two smaller cues. Costs plus benefits were greater at the element-sized cue $[F(1,51)=$ $48.82, p<.0003]$. The largest total costs plus benefits of cue validity effects occurred with the element-sized cue in the larger array [array size $\times$ cue size, $F(2,102)=$ $31.08, p<.0001$ ], and these effects of cue and array size were greatest in the young-old group [age group $\times$ array size $\times$ cue size, $F(4,102)=3.11, p<.05$ ], which is consistent with the results from the analysis of valid data. In order to further characterize these age-related changes in total cue validity effects, the condition producing the largest effect (the element-sized cue in the larger array) in the two elderly groups was found to be significantly negatively correlated with age $(r=-.343)$.

Combined search. An analysis of validly cued trials, in which the target was again defined by a conjunction of color and form, but in which no more than three pink items (target color) appeared on each trial, revealed that RT was slowed by increased levels of cue size $[F(2,102)=$ $51.39, p<.0001]$ and array size $[F(1,51)=38.01, p<$ $.0001]$. As in the conjunction condition, effects of cue size were greater when the array was large [array size $X$ cue size, $F(2,102)=5.21, p<.01]$. Also consistent with the conjunction condition, effects of cue size first increased, then decreased with age on combined search trials. Slopes of the cue-size/RT function followed this trend but did not differ significantly. In contrast with the conjunction condition, there was no significant interaction with age group in the combined condition. The main effect of age group was eliminated by the correction for generalized slowing.

In separate analysis of data from invalidly cued trials, the effect of target PA was examined. RT was slowed by target absence [PA, $F(1,51)=252.31, p<.0001]$, increased array size $[F(1,51)=6.37, p<.02]$, and increased cue size $[F(2,102)=208.99, p<.0001]$. Cue size effects were similar to those seen in the conjunction search, with a decrease in RT from the element-sized to the columnsized cue but an increase in RT from the column-sized to the large cue. These effects were greater when the array was large and the target present [PA $\times$ array size $\times$ cue size, $F(2,102)=3.68, p<.03$ ]. Cue size effects also increased with age, particularly when the target was present $[\mathrm{PA} \times$ cue size, $F(2,102)=7.81, p<.001 ; \mathrm{PA} \times$ cue size $\times$ group, $F(1,51)=4.88, p<.001]$. The main effect of age was not sustained after correction for slowing.

\section{Discussion}

\section{Feature Search}

According to the early form of FIT, feature search, associated with the phenomenon of popout, is carried out in parallel, independently of spatial attention (Treisman \& Gelade, 1980). Contrary to this view, the results of Experiment 1 showed that search speed for a target specified by a unique color was reduced with progressively smaller cues that pointed to the target location with increasing precision, particularly in a large array. These results are in accord with the later versions of FIT that propose a role for attention even in popout (Treisman, 1988).

As was suggested by a reviewer, acuity differences could account for the effects of precue size on popout. By this reasoning, a precue could produce an RT advantage when the target letter was located within the smallest precue by providing a stimulus for a saccade, resulting in foveation of the precued letter. The feasibility of this can be examined by considering latencies of saccades and RTs. At a cue-target SOA of $200 \mathrm{msec}$, mean RT for 


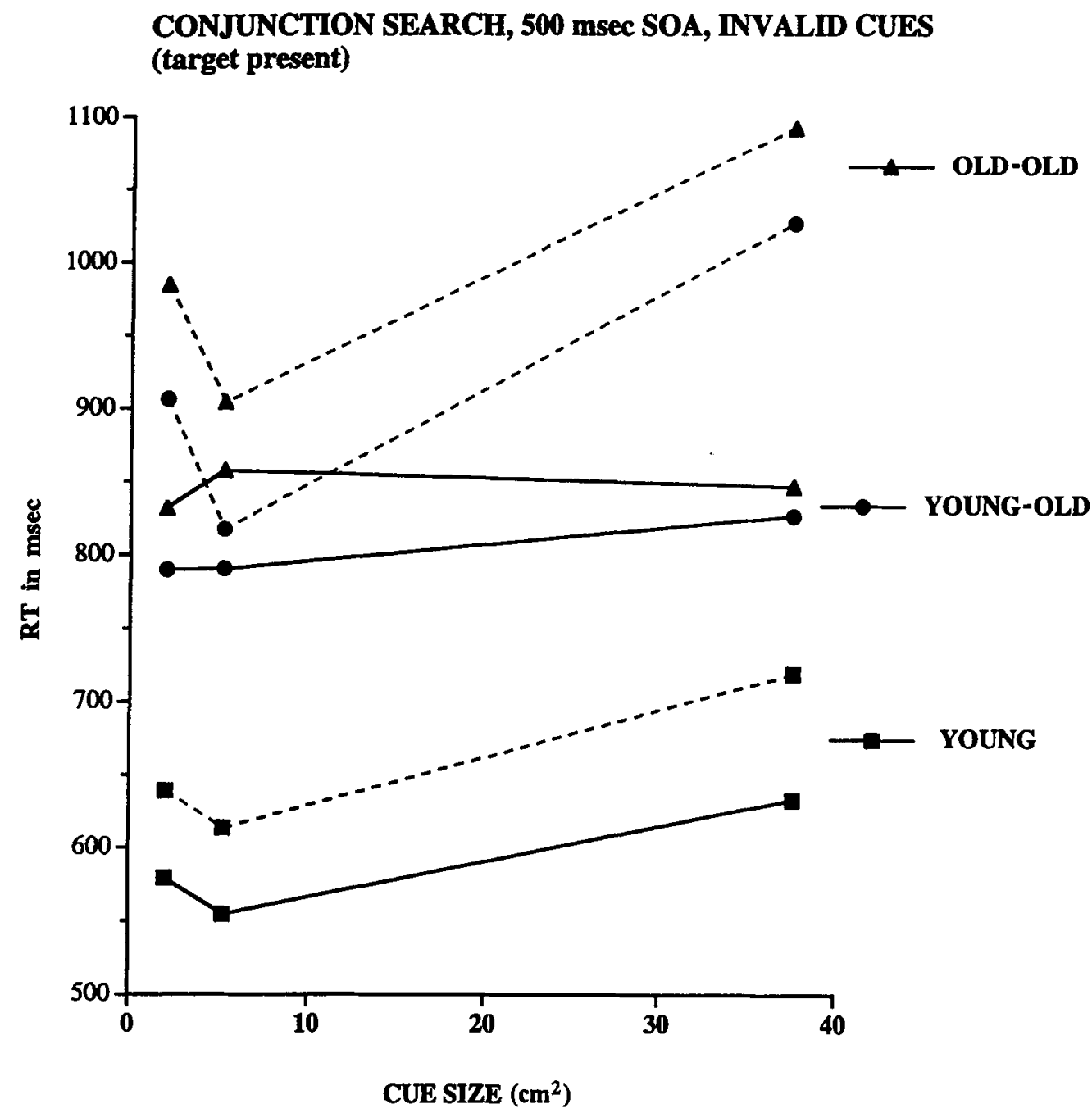

Figure 5. Reaction times (RTs) from invalidly cued conjunction search trials in Experiment 1 when the target was present, plotted as a function of cue size for array sizes 10 (solid lines) and 15 (dashed lines) for three age groups, with a 500-msec stimulus onset asynchrony (SOA).

the young group was $418.5 \pm 46.7$ and $430.9 \pm 51.14 \mathrm{msec}$ (for 10 and 15 element arrays, respectively). If a saccade was initiated at cue onset, taking on average $257 \pm 41 \mathrm{msec}$ for the eyes to begin to move (Carter et al., 1983), and vision is suppressed during the saccade (Carpenter, 1988), it can be assumed that target processing cannot take place until the saccade is completed (about 250-300 msec saccade duration in young in a search task; Zelinsky \& Sheinberg, 1997). Assuming the fastest saccade and the slowest RT, this leads to an estimate that from 199.2 to $216.3 \mathrm{msec}$ would be available between saccade completion and the response. The same reasoning in the youngold group, using feature search RTs of $520 \pm 56$ and $540.7 \pm 66.4 \mathrm{msec}$ (for 10 and 15 element arrays, respectively) and a saccade latency of $342 \pm 64 \mathrm{msec}$ (Carter et al., 1983), yields estimates of 248-279.1 msec (again, assuming $250-\mathrm{msec}$ saccade duration) for detection and response. Using slower saccade and faster RT estimates would lead to even lower estimates of time to process ar- rays after saccade completion. These values can be compared with simple RTs obtained in Experiment 2 of 241.1 $\pm 25.3 \mathrm{msec}$ in the young group and $292.5 \pm 44.0 \mathrm{msec}$ in the young-old group, suggesting that saccades to the precue could not have been completed in time for the reponse on most trials and were therefore probably not executed. RT latencies from uncued feature search trials would be more valid for this comparison, but such a condition was not used. The effect of the smallest precue on feature search was similar following 200- and 500-msec SOAs, even though completed saccades allowing foveation of the cued location before target appearance would be far more likely with a 500-msec SOA. In any case, the role of saccades in cued popout should be examined, either by using displays too brief for saccades (see, e.g., Triesman \& Gormican, 1988) or by recording eye movements.

That these cue effects on popout increased with age is consistent with reports of increased cue validity effects with age in nonsearch tasks (see, e.g., Greenwood \& Para- 
suraman, 1994; Greenwood et al., 1993). Results from invalid trials indicated that an attentional focus larger than an array element is deployed when search must proceed outside the cue. Finally, the slowing of search following the largest invalid cue suggests disengagement, and the increase in this effect with age is consistent with evidence from nonsearch tasks that disengagement is slowed in advanced age (Greenwood \& Parasuraman, 1994).

\section{Conjunction Search}

Location precues influenced conjunction search in the same manner as they did feature search, although the cue effects were larger. The participants were progressively quicker to detect a conjunction of color and form as the precue decreased in size from the whole array to a column to a single item. Moreover, these effects of the precision of valid precues were heightened from youth to old age but then declined in advanced old age, extending our previous report of a reduction in cue-size effects in search with both advanced age and the onset of DAT (Greenwood et al., 1997; Parasuraman et al., 1995). The present results also provide a context for interpreting the reduced benefit of valid cue precision seen in individuals with mild DAT, as compared with healthy elderly, by Parasuraman et al. (1995). Whereas that study showed that the benefits of cue precision decreased with age and DAT, the present results indicate that this decrease is relative to an increase from youth to old age.

In contrast with the case with validly cued trials on which conjunction search was most facilitated by element-sized precues, on invalidly cued trials element-sized precues slowed search more than did column-sized precues (Figure 6). Age did not alter this effect. The slowing of RT by invalid precues as precue size increased from column size to array size also increased with age. As was suggested for feature search, this may indicate that the optimal size for the attentional focus when searching outside the cue is one larger than array elements. All the effects of precue precision were stronger with a larger array, suggesting further that there is a certain critical array size, below which size precues are less effective, regardless of age.

\section{Combined Search}

The results for combined search trials, in which there was a small number of target color distractors, were similar in direction, but not in degree, to those from conjunction search trials with a large number of target color distractors. Compared with the conjunction search condition, the smaller number of target color items present in the combined condition reduced the effects of both age and precue size.

\section{Summary}

To summarize, precues appearing in the target location speeded all forms of search when precise but slowed search when imprecise. Conversely, precues appearing away from the target speeded search when only moderately precise but slowed search both when very precise and when very imprecise. These results can be interpreted by assuming that precues influence participants' scale of attentional focus. When attention is narrowly focused on a small area by a small precue, a target appearing in that area is detected more rapidly, as compared with cases in which attention is more broadly distributed (see, also, Eriksen \& Yeh, 1985; LaBerge \& Brown, 1989). However, a medium-sized area of attentional focus appears optimal when the target does not appear in the cued area.

This explanation would be strengthened if these effects could be shown to vary with cue-target interval. An alternative explanation, suggested by an anonymous reviewer, attributes the effects of cue size to search strategy. By this view, once the array is presented, the participants would first search inside the cued region (presumably without eye movements), then search outside the cued region. Although this explanation has no greater explanatory power than one based on the scale of the attentional focus, it has the virtue of simplicity. Such a view would predict that cuing effects should be relatively impervious to the interval between the cue and the search array, because the effects of cues are manifest only once the array is displayed. Use of a strategy once the cue and the target are presented should not be subject to variations in the cue-target interval. In contrast, adjustment of the scale of the attentional focus can be predicted to require time, on the basis of a literature showing that, although peripheral location cues are effective in facilitating target discrimination as quickly as $50 \mathrm{msec}$ after cue onset, central, symbolic location cues require considerably more time to be effective (Greenwood \& Parasuraman, 1994; Müller \& Rabbitt, 1989), presumably because such a cue must be interpreted before attention can be shifted.

Experiment 2 was undertaken to test this interpretation. In a separate sample of young and old adults, the design of Experiment 1 was altered only by changing the SOA from 500 to $200 \mathrm{msec}$. An explanation based on posttarget search strategy would predict no effect of cue-target SOA. An explanation based on pretarget adjustments in the scale of the attentional focus would predict that a brief SOA would be insufficient for cuing effects to develop. Furthermore, adjustment of the scale of the attentional focus would perhaps take more time, since smaller cues induce a smaller attentional focus. Castiello and Umiltá (1990) observed, with a nonsearch task, that cue effects were not seen at a $40-\mathrm{msec}$ SOA but had developed by $500 \mathrm{msec}$. Therefore, it was further predicted that effects of SOA would be greater for the element-cue size.

\section{EXPERIMENT 2}

This experiment employed the same design as that in Experiment 1, differing only in the SOA, which was changed from 500 to $200 \mathrm{msec}$. 


\section{COMBINED SEARCH, 500 msec SOA, VALID CUES}

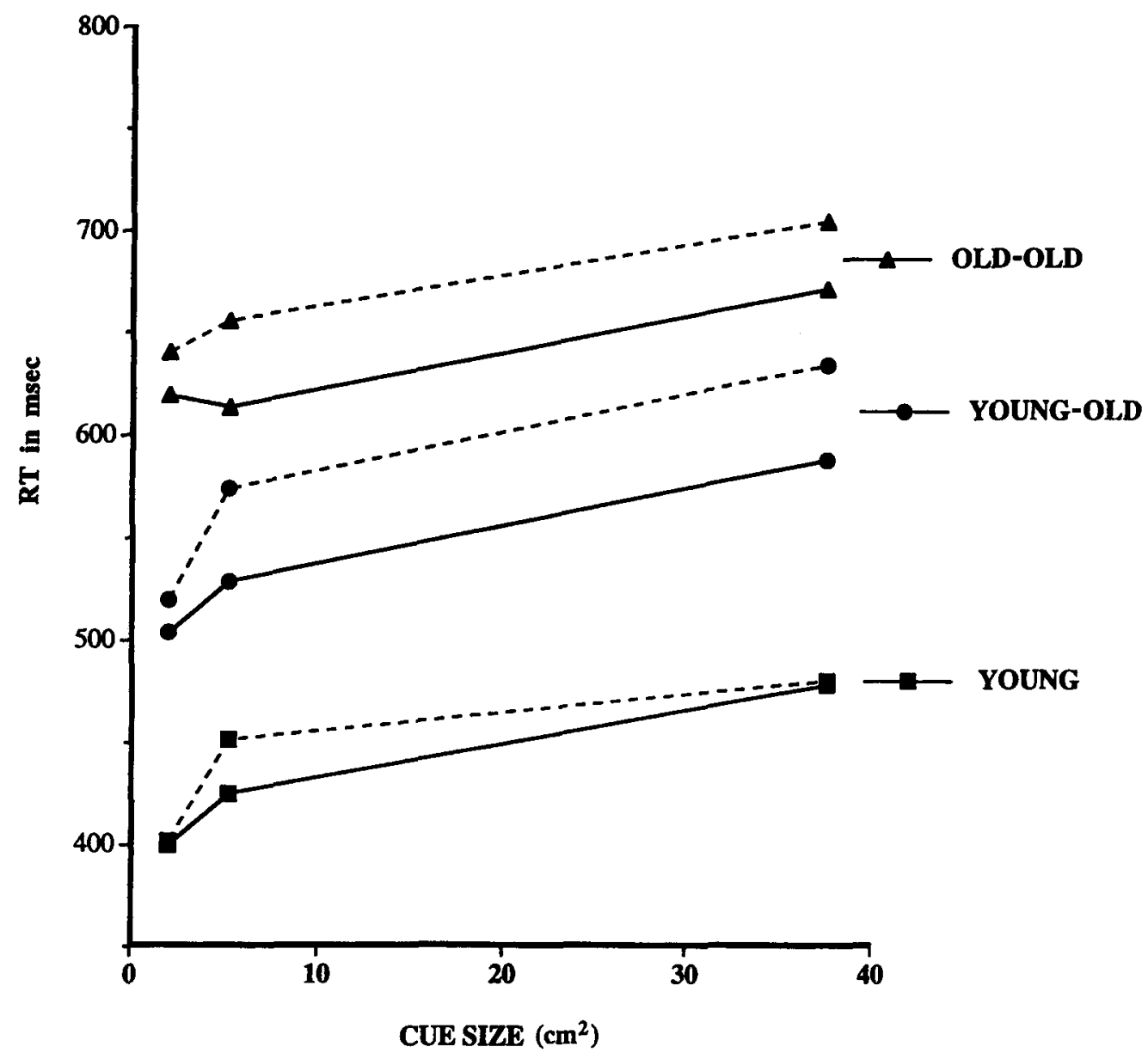

Figure 6. Reaction times (RTs) from validly cued combined search trials in Experiment 1, plotted as a function of cue size for array sizes 10 (solid lines) and 15 (dashed lines) for three age groups, with a 500-msec stimulus onset asynchrony (SOA).

\section{Method}

The participants were 10 undergraduates, 18-25 years of age, who were fulfilling course requirements by their participation, and 10 elderly community-dwelling individuals, who were paid for their participation. Characteristics of the two groups are presented in Table 3. The groups differed significantly only in education $(p<$ $.03)$ and WAIS vocabulary $(p<.05)$.

\section{Results}

\section{Accuracy}

In general, accuracy was quite high, ranging from $100 \%$ for the young group on combined search trials to $83 \%$ for the old group on conjunction search. ANOVAs gave significant effects for age group $[F(1,18)=4.96$, $p<.05]$ and validity $[F(1,18)=9.68, p<.01]$ and for interactions of task $\times$ validity $[F(2,36)=4.23, p<.05]$, validity $\times$ cue size $[F(1,36)=5.03, p<.01]$, and validity $\times$ cue size $\times$ age group $[F(2,36)=4.08, p<.03]$.

\section{Reaction Times}

As in Experiment 1, an omnibus ANOVA of proportional RT scores yielded a main effect of task $[F(2,36)=$ $11.70, p<.001$ ], justifying separate analyses for each task. The numerous other significant effects in the omnibus ANOVA are not listed here, because analyses from each of the three tasks are detailed separately below.

Feature search. For validly cued trials, as in Experiment 1 , when precues were valid there were effects of cue size on feature search that were altered both by array size and by age (Figure 7). RTs were slower overall in the old group $[F(1,18)=17.16, p<.0001]$, particularly with the larger array [array size, $F(1,18)=80.36, p<$ .0001 , and array size $\times$ group, $F(1,18)=5.24, p<.03$ ] Although RT increased overall with cue size $[F(2,36)=$ $2.95, p<.05]$, this effect was modified by age group [cue size $\times$ age group, $F(2,36)=3.90, p<.03$ ], so that the elderly were slower when the cue was element sized 
Table 3

Means and Standard Errors of Demographic Characteristics of Participant Groups in Experiment 2

\begin{tabular}{lccccc}
\hline & \multicolumn{2}{c}{ Young } & & \multicolumn{2}{c}{ Young-Old } \\
\cline { 2 - 3 } & $M$ & $S E$ & & $S$ & $S E$ \\
\hline Number & 10 & & & 10 & \\
Female/Male & $6 / 4$ & & & $5 / 5$ & \\
Age (years) & 18.7 & 0.26 & & 70.3 & 0.93 \\
Education (years) & 12.5 & 0.22 & & 14.4 & 0.85 \\
WAIS vocabulary & 46.0 & 2.09 & & 55.6 & 3.85 \\
Logical memory (WMS) & & & & \\
$\quad$ Immediate & 12.5 & 1.17 & & 11.1 & 0.94 \\
$\quad$ Delayed & 12.5 & 1.44 & 9.1 & 1.04 \\
\hline
\end{tabular}

than when it was column sized in the larger array. The interaction of cue size with array size was marginal in the uncorrected analysis $(p<.07)$ but reached significance after correction for generalized slowing $[F(2,36)=3.46$, $p<.05]$. There was no interaction of cue size $\times$ age group. Correction for generalized slowing eliminated the significance of the main effect of age but altered the other effects only as indicated above.

For invalidly cued trials, when the precues were invalid, the old were slower than the young overall $[F(1,18)=$ $10.66, p<.005]$. Also, as in Experiment 1, RT was slower when the array was larger $[F(1,18)=11.63, p<$ $.003]$ and precues were column sized, rather than element sized or array sized $[F(2,36)=126.62, p<.0001]$. This effect of cue size interacted with the PA of the target [PA $\times$ cue size, $F(2,36)=14.21, p<.0001]$ and with array size [PA $\times$ cue size $\times$ array size, $F(2,36)=3.64, p<$ $.05]$. There was also a four-way interaction with age group [PA $\times$ cue size $\times$ array size $\times$ age group, $F(2,36)=$ $3.39, p<.05]$. Correcting this data for age-related slowing eliminated the main effect of age group but did not alter the other main effects of array size and cue size. Adjustment eliminated the other interactions, except for that of PA $\times$ cue size $[F(2,36)=16.27, p<.0001]$. To examine the effect of invalid cue size without the need to shift attention across the screen, data from the two smaller cues were analyzed separately. This produced the expected main effects of age group $[F(1,18)=10.88, p<.004]$ and array size $[F(1,18)=9.79, p<.01]$, owing to longer RTs in the old and with the larger array. Effects of cue size did not produce a main effect, but cue size interacted with array size $[F(1,18)=5.53, p<.03]$, reflecting increased RT with increased cue size from the element-sized to the column-sized cue in the small array but a decrease in the larger array (Figure 8). The lack of interactions between cue size and group indicates that age did not alter these effects of invalid cue size.

The increase in RT from the column-sized to the arraysized cue on invalid trials is a combined estimate of the effects of increasing cue size and shifting attention across the screen. An analysis of this measure produced a significant effect of array size $[F(1,18)=67.67, p<.0001]$ and a marginal interaction of array size $\times$ age group $[F(1,18)=4.04, p<.06]$, reflecting the particular increase in RT in the old group in the smaller array.
Conjunction search. For validly cued trials, validly cued conjunction search RTs slowed as precue size increased, particularly when the array was large (Figure 9). RTs increased with age $[F(1,18)=20.61, p<.001]$, array size $[F(1,18)=93.04, p<.0001]$, and cue size $[F(2,36)=37.57, p<.0001]$. The effects of cue size were greater with the larger array [cue size $\times$ array size, $F(2,36)=7.83, p<.003$ ], as were the effects of age [age group $\times$ array size, $F(1,18)=9.39, p<.01]$. This latter effect did not survive correction for age-related slowing, although all the other effects did survive such correction, including the main effect of age group. The effects of cue size did not interact with age, nor did age affect the slopes of the cue-size/RT function (Table 2).

For invalidly cued trials, an analysis of invalid conjunction search trials revealed that RT was slowed by age $[F(1,18)=8.70, p<.01]$, target absence $[F(1,18)=$ $337.95, p<.0001]$, and a larger array $[F(1,18)=154.98$, $p<.0001]$. Figure 10 shows that RT was also slowed by element-sized precues, as compared with column- and array-sized precues $[F(2,36)=41.50, p<.0001]$, particularly when the array was large and the target was present [PA $\times$ array size, $F(1,18)=32.57, p<.0001$, and PA $\times$ array size $\times$ cue size, $F(2,36)=13.50, p<.0001]$. The only significant interaction involving age group was $\mathrm{PA} \times$ group $[F(1,18)=29.51, p<.0001]$, although there were marginal interactions of array size $\times$ group $(p<.06)$ and PA $\times$ array size $\times$ group $(p<.07)$. Correcting these data for overall age effects eliminated the main effect of age group and altered the other effects only by adding significant interactions of PA $\times$ cue size $[F(2,36)=45.71$, $p<.0001]$, cue size $\times$ array size $[F(2,36)=46.94, p<$ $.0001]$, and cue size $\times$ array size $\times$ group $[F(1,18)=4.42$, $p<.02]$.

Combined search. For validly cued trials, in what was termed the combined search condition, either two (target absent) or three (target present) target color array elements appeared within each array, allowing the participants to confine their search to the target color items. As was discussed in Experiment 1, this condition allows assessment of the search strategy employed. The results are similar to those of the conjunction search condition, with RT slowed by age $[F(1,18)=16.65, p<$ $.001]$, increased array size $[F(1,18)=19.35, p<.0002]$, and increased cue size $[F(2,36)=30.24, p<.0001]$. The three-way interaction of array size $\times$ cue size $\times$ age group $[F(2,36)=5.06, p<.01]$ was unexpected and did not survive adjustment for generalized slowing. The adjustment for generalized slowing also eliminated the main effect of age but added a significant interaction of cue size $\times$ age group $[F(2,36)=11.64, p<.001]$. This interaction appears to be due to the reduced effect of the largest cue in the elderly group. This effect was also seen in conjunction search (Figure 9), but it did not reach significance in that condition. Finally, slopes of RT/cue-size functions did not distinguish between groups or array size.

For invalidly cued trials, RT was slowed by age $[F(1,18)=10.38, p<.01]$, particularly when the target 


\section{FEATURE SEARCH, 200 msec SOA, VALID CUES}

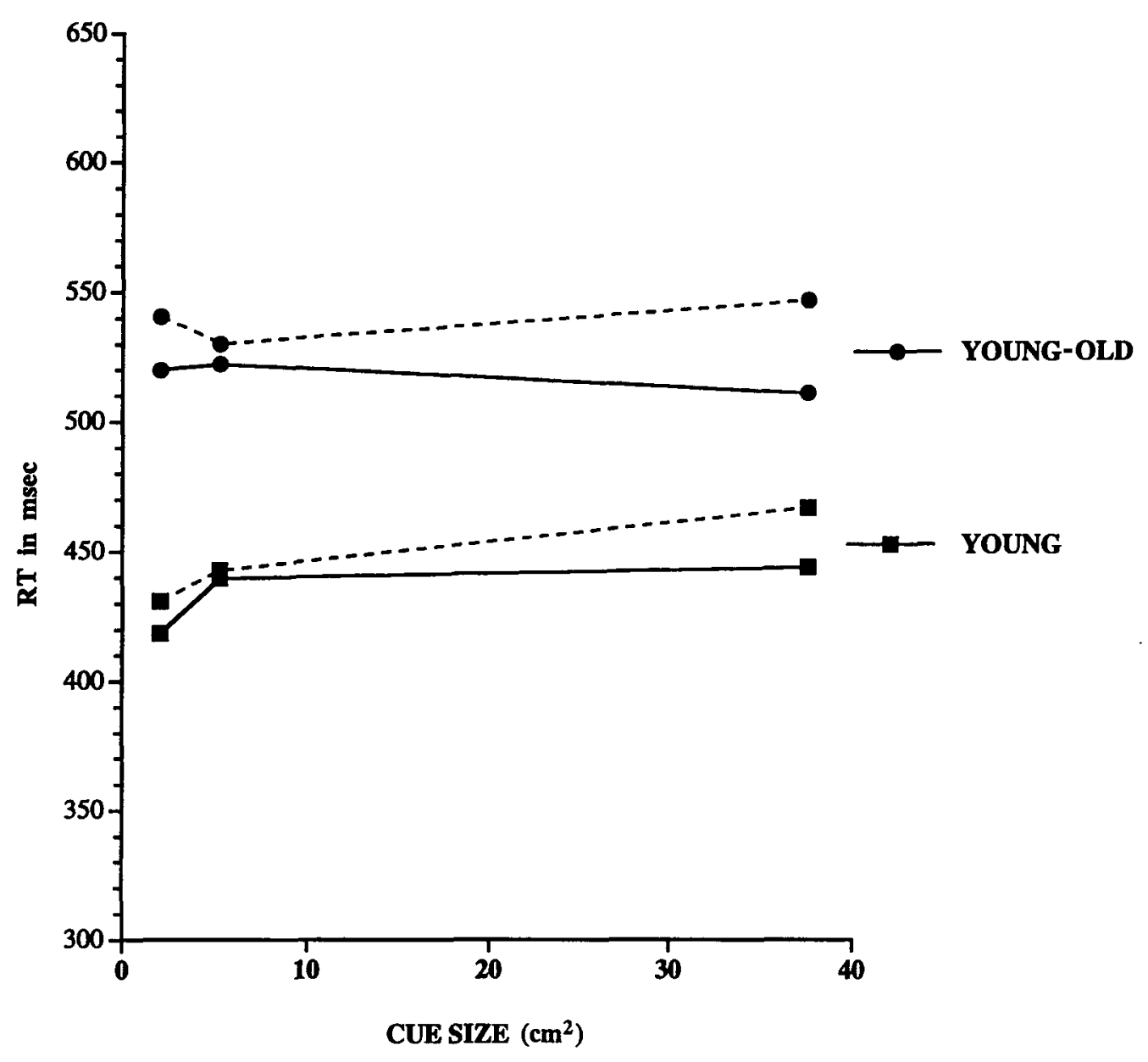

Figure 7. Reaction times (RTs) from validly cued feature search trials in Experiment 2, plotted as a function of cue size for array sizes 10 (solid lines) and 15 (dashed lines) for two age groups, with a 200-msec stimulus onset asynchrony (SOA).

was absent $[\mathrm{PA}, F(1,18)=107.68, p<.0001$, and $\mathrm{PA} \times$ age group, $F(1,18)=13.49, p<.002]$. RT also varied with cue size $[F(1,18)=67.04, p<.0001]$, being speeded slightly from the element-sized to the column-sized cue, then slowed with the array-sized cue. These factors all interacted [PA $\times$ array size $\times$ cue size $\times$ age group, $F(2,36)=3.53, p<.05]$.

\section{Feature Search}

\section{Discussion}

As in Experiment 1, in Experiment 2 size and location precues altered the rate of popout, particularly with the 15 -item array. The shorter SOA of Experiment 2 was associated with smaller effects, particularly of the larger precue size, as compared with those of Experiment 1. In Experiment 1, the slowing of popout associated with increased size of valid precues was greatest in the old-old elderly participants. In Experiment 2, the effect was changed in form, so that, particularly with the larger array, the benefit of the most precise cue in the young and young-old groups with an SOA of $500 \mathrm{msec}$ in Experiment 1 became a cost in the young-old group when the SOA was reduced to $200 \mathrm{msec}$ in Experiment 2. Therefore, shortening the SOA not only reduced the effects of cue size, but also changed the nature of the effects in the old participants.

Invalid precue size also altered search $\mathrm{RT}$ in a manner similar to that in Experiment 1. When the target was present, an invalid element-sized precue tended to slow popout more than did a column-sized precue. Popout was slowed most when the precue was array sized. Regardless of SOA, in the elderly participants the benefit of the most precise cue with the smaller array became a cost with the larger array. 


\section{FEATURE SEARCH, 200 msec SOA, INVALID CUES (target present)}

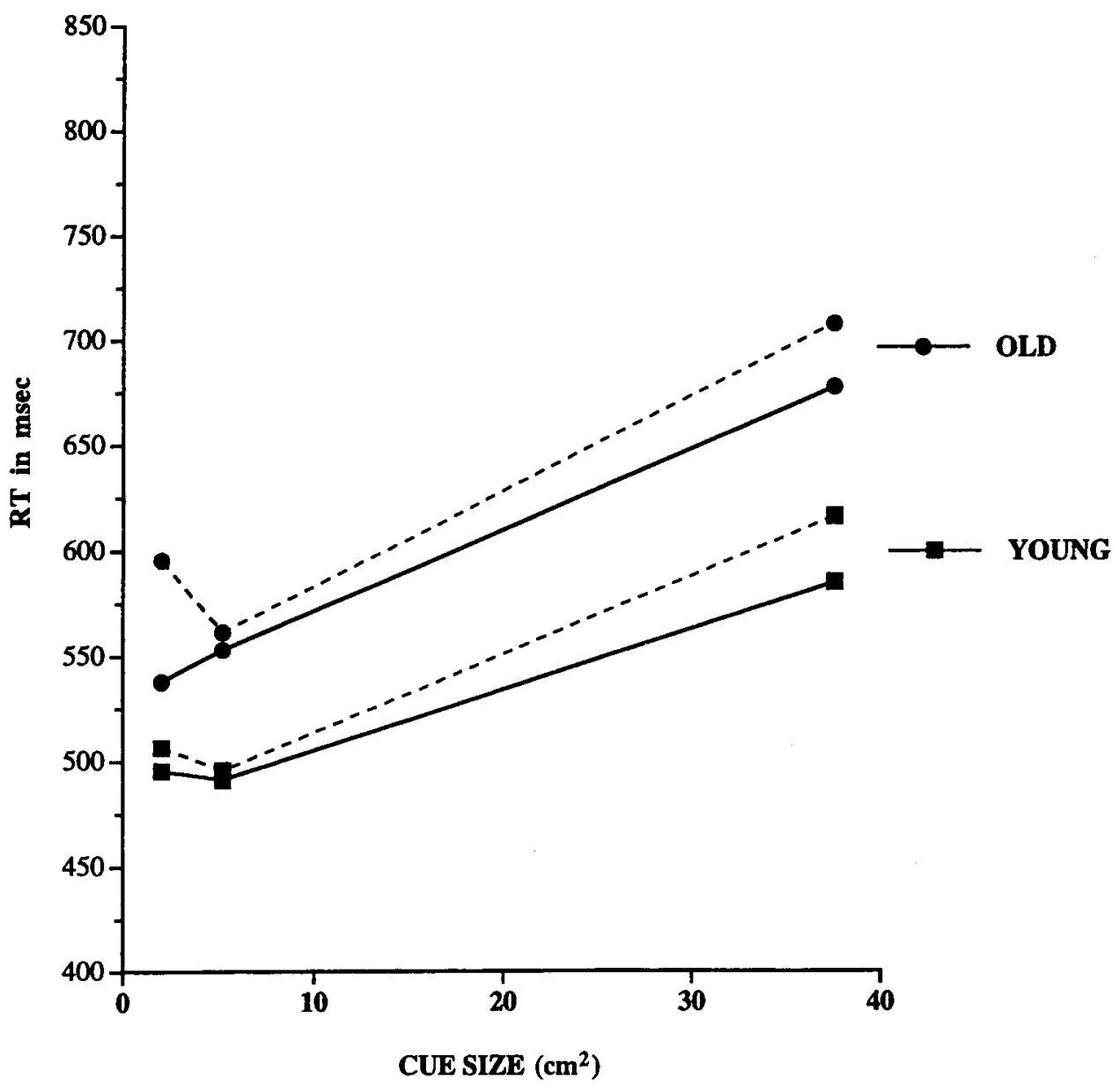

Figure 8. Reaction times (RTs) from invalidly cued feature search trials in Experiment 2 when the target was present, plotted as a function of cue size for array sizes 10 (solid lines) and 15 (dashed lines) for two age groups, with a 200-msec stimulus onset asynchrony (SOA).

\section{Conjunction Search}

Although RT increased with valid cue size, the effect was smaller than that observed in Experiment 1, in which the SOA was longer. Age effects were also reduced. A comparison of Figures 4 and 9 suggests that the shorter SOA in Experiment 2 particularly reduced the slowing effect of the array-sized cue. These effects were reflected in the cue-size/RT slopes. The increase in slope with array size in the young-old group in Experiment 1 was present, but was smaller, in Experiment 2. Although slope values varied with age and array size in Experiment 1, they did not do so in Experiment 2.

Similarly, the effects of invalid cues resembled those from Experiment 1, with RT slower following the elementsized precue, as compared with the column-sized precue, when the array was large. As was the case with valid cues, the invalid cue-size effects were smaller than in Experiment 1 , and the age effects did not reach significance.
Taken together, the results from Experiment 2 confirm the general trends of Experiment 1 but indicate that, as hypothesized, the SOA used in Experiment 2 was insufficient for the effects to develop.

\section{Combined Search}

The effects of precue size in this condition were similar to those seen for conjunction search. As in Experiment 1 , limiting the number of target color items speeded search and reduced the effects of all the factors. The reduction in RT between the two conditions was particularly marked in the elderly participants (means of 625.7, 667.3, and 706.3 for the three cue sizes, respectively, on conjunction search trials and $580.4,600.4$, and 631.9 on combined search trials). This may be attributed to reduced search demand when the number of target-relevant items was small, suggesting that both search speed and reliance on precues diminish with reduced search de- 


\section{CONJUNCTION SEARCH, 200 msec SOA, VALID CUES}

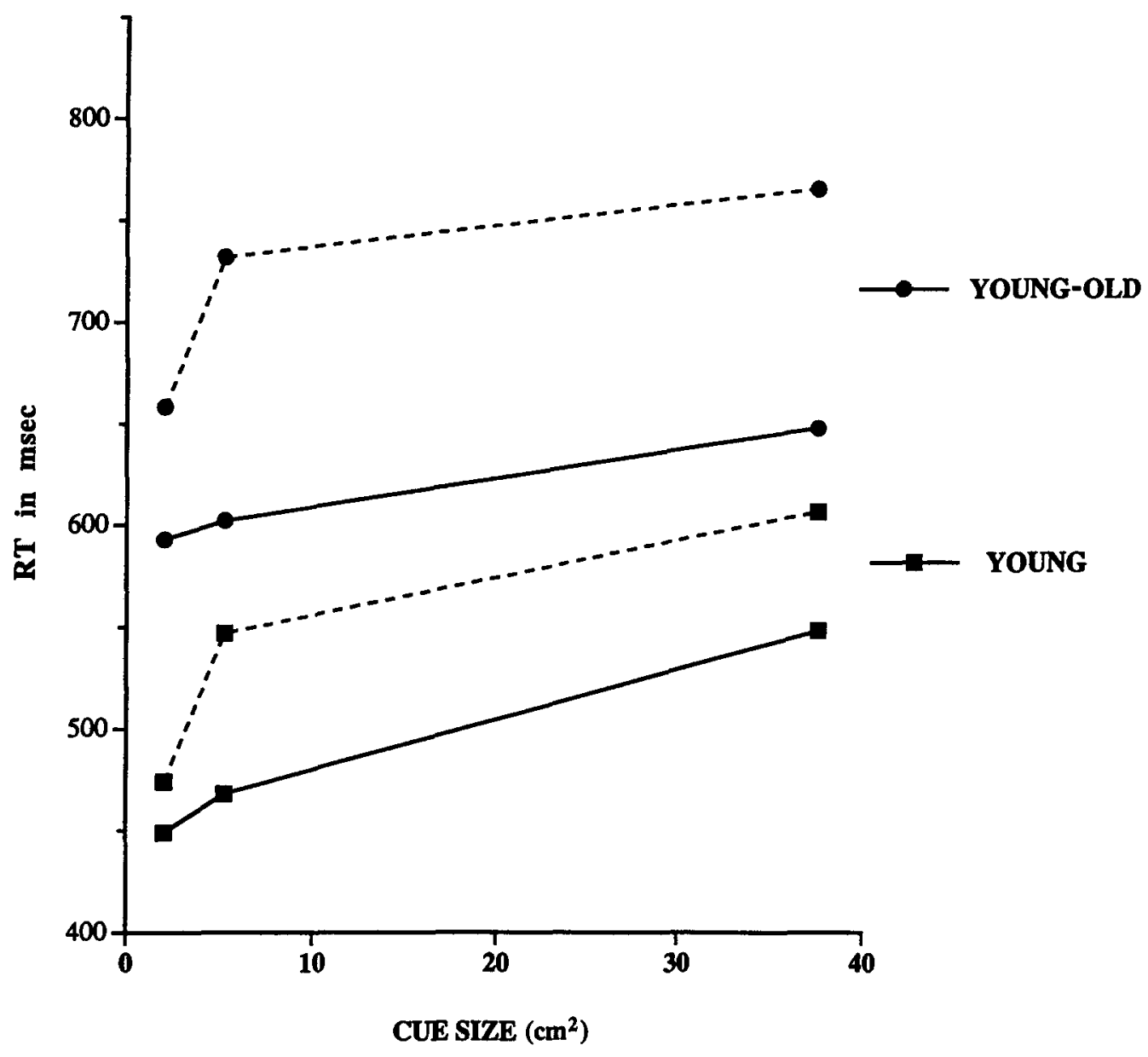

Figure 9. Reaction times (RTs) from validly cued conjunction search trials in Experiment 2, plotted as a function of cue size for array sizes 10 (solid lines) and 15 (dashed lines) for two age groups, with a 200-msec stimulus onset asynchrony (SOA).

mand. The effect of age on combined trials may have been small because the searching requirements were less. For all the groups, combined search was faster overall than conjunction search, suggesting that all the participants were able to confine search to the target color items, consistent with the conclusion of Plude and Doussard-Roosevelt (1989) that the elderly are as able as the young to efficiently confine search to a relevant subset of array items.

\section{Summary}

Overall, a comparison of the results from Experiment 2 with those from Experiment 1 indicates that a short interval between the cue and the target tends to reduce the benefit of precue precision, particularly in the elderly. This reduction in the cue-size effect occured in all the search conditions but was most pronounced for the conjunction search, for which the effects of cue size were also greatest. These data can be interpreted as suggesting the existence of a time course in the development of effects of cue size that is slowed in the elderly.

These findings show that location and size precues alter the speed of visual search and that these effects are strongest with (1) large search arrays, (2) longer SOAs, and (3) more difficult search conditions. Furthermore, Experiment 1 showed that the effect of precues are larger in the young-old than in the young, but then decline further with advanced aging. Experiment 2 indicated that precue effects depend on the SOA employed, so that cue effects are weaker when there is insufficient time for cue effects to develop. Similar effects of SOA with symbolic location precues have been observed in nonsearch tasks in which an SOA of $200 \mathrm{msec}$ was insufficient to elicit cuing effects in time to discriminate a target (Greenwood 


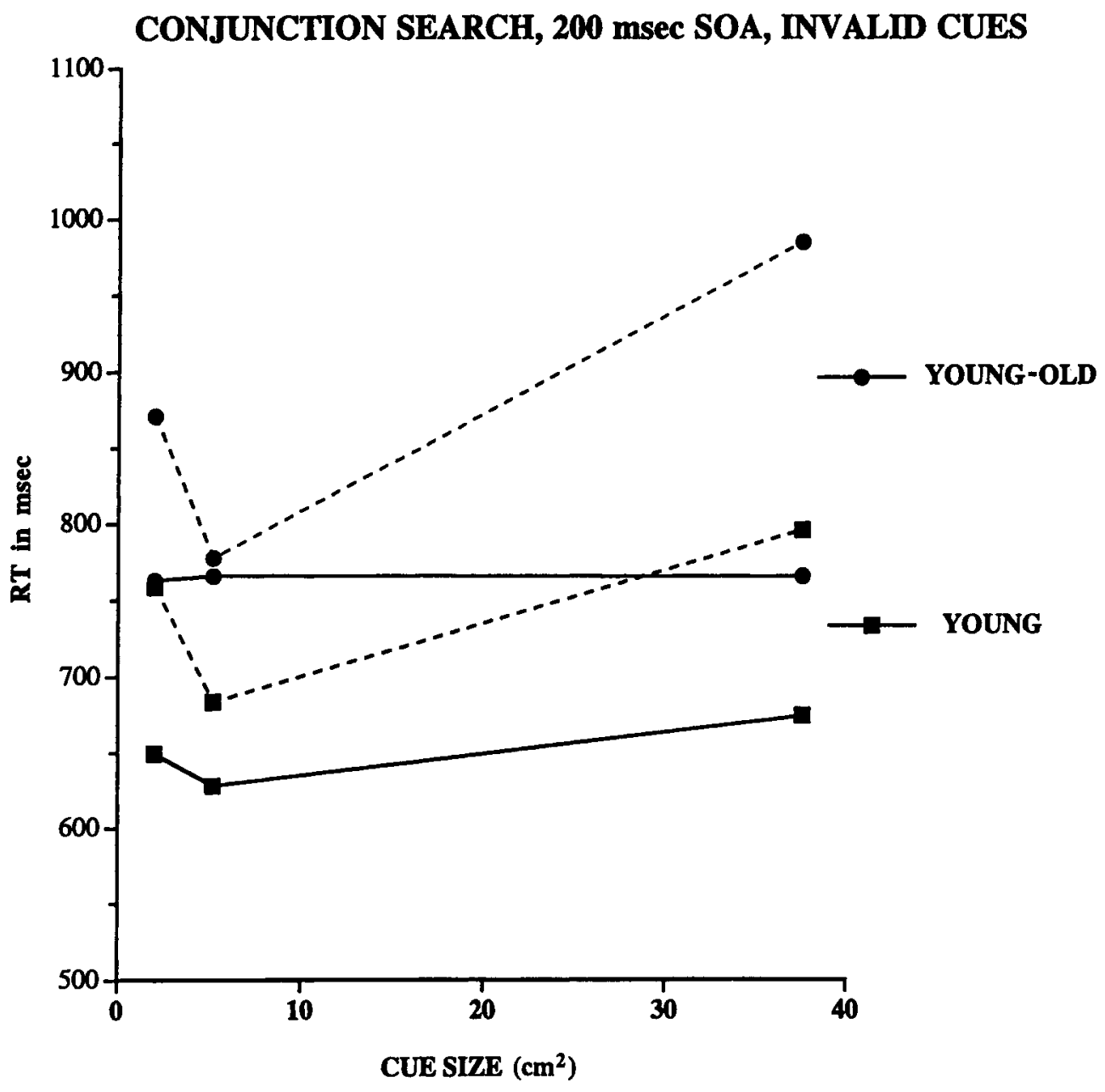

Figure 10. Reaction times (RTs) from invalidly cued conjunction search trials in Experiment 2 when the target was present, plotted as a function of cue size for array sizes 10 (solid lines) and 15 (dashed lines) for two age groups, with a 200-msec stimulus onset asynchrony (SOA).

\& Parasuraman, 1994; Greenwood et al., 1993; Müller \& Findlay, 1988). These results argue against a strategybased explanation of cue-size effects, given that the use of such strategies should not be influenced by the cue-target interval. Instead, the results are consistent with the view that size precues result in dynamic alteration of the scale of attentional focus, a process that requires sufficient time to develop.

\section{GENERAL DISCUSSION}

\section{Spatial Attention and Visual Search}

The present results indicate that the scale of spatial attention influences the efficiency with which objects can be identified among distractors in a complex visual field. Dynamic changes in the scale of the attentional focuswhether narrowly focused or more broadly distributedcan be induced by giving participants location precues that vary in size and, hence, in precision to target location. Two experiments showed that cue-induced changes in the scale of the attentional focus affected the speed of target detection during visual search. Search RT was reduced with progressively smaller cues that pointed to the target location with increasing precision. Both feature and conjunction search were facilitated. These results are consistent with the view that spatial attention influences the efficiency of search, regardless of the type or difficulty of the search task (Briand \& Klein, 1987; Greenwood et al., 1997; Prinzmetal et al., 1986).

Narrowly focused attention, as induced by a small location precue, facilitated target detection when the cued area of the attentional focus included the target. This finding had been observed previously in a nonsearch detection task (Castiello \& Umiltà, 1990), but the present results show that dynamic changes in the scale of the attentional focus also influence the efficiency of search for an object among distractors. Furthermore, the present study shows that the effect varies with the task. That these effects of cue size were greater on conjunction than on feature search trials is consistent with the postulated 
greater dependence of conjunction search on spatial attention (Prinzmetal et al., 1986; Treisman, 1996).

Furthermore, the effects of precue precision develop over time, as is shown by the manipulation of SOA between Experiments 1 and 2. Cue-size effects were greater for an SOA of $500 \mathrm{msec}$ than for an SOA of $200 \mathrm{msec}$. A time course for location cue effects in nonsearch tasks has been reported previously (Castiello \& Umiltà, 1990; Greenwood \& Parasuraman, 1994; Greenwood et al., 1993; Müller \& Rabbitt, 1989). Preliminary evidence from an ongoing study indicates that the effects of precue size increased in young participants with increased SOA (Faust, Balota, \& Duchek, 1996). In that study, the effects of cue size on search in the elderly are well developed by $200 \mathrm{msec}$, in contrast with the present study, in which the effects of cue size were stronger at the 500than at the 200-msec SOA. Another study manipulating SOA found the strongest effects of precue size at a 750msec SOA (Greenwood \& Parasuraman, 1996). These studies used centered arrays, in contrast to the lateralized arrays employed in the present experiments, suggesting that the speed at which cue effects develop depends on task variables.

The existence of a time course in the development of precue effects argues against explanations based on the use of a posttarget search strategy. A search strategy could not operate before the array was present, so the time between cue onset and array onset should be irrelevant to speed of target detection. Yet a longer cue-target SOA was associated with greater effects of precue size on conjunction search. Therefore, we conclude that the size of location precues serves to affect the scale of the observer's attentional focus and this, in turn, alters speed of target detection.

Evidence from the present studies further suggests that, in young individuals, the time course of precue effects is different for feature and conjunction search. In feature search, with lateralized arrays, cue effects were evident in the young participants at the shortest SOA of $200 \mathrm{msec}$. In nonsearch paradigms, the development of peripheral cue effects is maximal around $200 \mathrm{msec}$ (Colegate, Hoffman, \& Eriksen, 1973; Eriksen \& Collins, 1969; Nakayama \& Makeben, 1989). In the present study, in feature search, the cost of small precues was also present at a 200-msec SOA. These results indicate that, in feature search, as in nonsearch cued tasks, the effects of peripheral precues develop rapidly. In contrast, in conjunction search, cue effects on RT are not maximal at $200 \mathrm{msec}$ (Figures 4 and 9). Increasing task difficulty is known to slow the development of the effects of central, symbolic, location precues in nonsearch tasks (Greenwood \& Parasuraman, 1994); the present study has likewise shown that, in search tasks, the effects of precue size were greater with larger arrays and with harder discriminations.

That the speed of both feature and conjunction search was influenced by precue size is incompatible with the original formulation of FIT (Treisman \& Gelade, 1980), which proposed that a conjunction search requires re- peated shifts of spatial attention to bind elementary features, whereas a search for single features is parallel and does not require such a mechanism. More recent manifestations of Treisman's two-component theory claim that, although serial attentional shifts are more important in conjunction search, they are part of feature search as well (Cave \& Wolfe, 1990; Treisman, 1988; Treisman, 1996). The results of the present study are more consistent with these latter formulations.

The effects of precue size on feature search are consistent with our previous work showing that popout is influenced by the scale of the attentional focus (Greenwood et al., 1997; Parasuraman et al., 1995). They are also consistent with other reports of top-down effects on popout. Varying the designated target of feature search slows popout (Treisman \& Gormican, 1988) and delays the latencies of event-related potential components $\mathrm{P} 2, \mathrm{~N} 2$, and P3 evoked by the target (Luck \& Hillyard, 1994). Topdown effects on popout are more in line with the view of Duncan and colleagues that feature and conjunction searches are not separate entities with different mediations but, rather, are points on a continuum of search difficulty (Duncan \& Humphreys, 1989). Desimone and Duncan (1995) proposed that competition between neural elements underlies both feature and conjunction search and that both are subject to a top-down biasing mechanism associated with the prefrontal cortex. This mechanism acts to direct and resolve the bottom-up competition for neural processing proposed to occur between stimulus elements. According to this theory, both types of search would be subject to the top-down influence of precue size. However, Duncan's theory cannot account for reduced top-down effects of cue size on feature search, since it does not provide for variations in top-down effects. Cave and Wolfe's (1990) GST theory has some provision for variation in top-down activation across feature dimensions (e.g., color and size), which might perhaps be extended to predict differential guidance on the basis of the precision of information about target location.

An explanation of popout has been offered by Nakayama and colleagues (Nakayama, 1990; Nakayama \& Joseph, 1998), who also reject the notion of separate serial and parallel search processes and propose, rather, that the spatial scale changes in the course of feature search. In this view, popout occurs when, following an initial allocation of attention to the entire array, attention is involuntarily narrowed to an odd item. This notion that, in feature search, the attentional focus is first broad, then narrow, does not explain the results from validly cued trials in Experiments 1 and 2, since the observed facilitation of popout by a valid, target-sized precue does not suggest broadening of the spatial scale. It may be, however, that the continued presence of the location precue could eliminate the need for Nakayama's hypothesized second phase of narrowing the attentional focus by the continued presence of the location precue.

The results of the present experiments suggest that both the scale and the rate of change in the scale of the 
attentional focus may change with the requirement to actively search. Since no current theory is able to address the full range of results from the present manipulations of precue size in search tasks, we offer our own views. Because size and location precues are seldom present in daily life where processes of search are frequently deployed, a meaningful explanation of precue effects needs to consider the ways in which the attentional focus is scaled spontaneously in search. There are several processes that can be deployed as tools in visual search, including head movements, saccadic eye movements, shifts in position of the attentional focus, and dynamic adjustments of the scale of the attentional focus. We postulate that not all these tools are used in every instance of the need to search but, rather, each is deployed independently, depending on the demands of the search task. Furthermore, the speed with which these tools are deployed varies with task demand.

First, relatively few saccades are made in search tasks (Previc, 1996), possibly because saccades take several hundred milliseconds to initiate (Carter et al., 1983) and vision is suppressed during saccades (Carpenter, 1988). Therefore, scanning with the attentional focus presumably occurs within fixations. Second, we postulate that having the attentional focus scaled to target size before the search array appears facilitates search, but only when the target is located inside the attentional focus, thus eliminating the need to shift the attentional focus. In the real world, such scaling might be initiated by top-down information about target size, whereas cues to target location might be provided by motion. In any case, the benefit of a focus scaled to target size accrues to both feature and conjunction search but increases with task difficulty. In the present studies, the effects of cue size increase both with array size and with increased task difficulty from feature to conjunction search. In the present studies, the additional search time required when a valid precue was larger than the target could be due either to (1) scaling the attentional focus to target size or (2) scanning within the focus. Third, a narrow attentional focus is not always maximally efficient, given that different dynamics apply when the attentional focus is not located at the target and active search is required. In the present studies, when precues were invalid, a larger than element-sized attentional focus was optimal for the active searching needed to locate the target (Figures 5 and 10). The slowing of search following an invalidly located element-sized precue may be attributed to the need to broaden the scale of the attentional focus. It can be postulated that the optimal scale for active searching within an array is one sufficiently broad to encompass several array elements in order to facilitate processes of pattern recognition. This view that visuospatial attention possesses properties of shifting in space and varying in scale is thus able to account for the results from invalidly cued trials, unlike that of Nakayama and Joseph (1998). Finally, when arrays are relatively small and one-dimensional, such as those used in the flanker paradigm (LaBerge, Carlson, Williams, \& Bunney, 1997), a large attentional focus with properties of a gradient may be employed.

The present results and our interpretation may help to reconcile the two dominant views of the attentional focus, the spotlight model inherent in Treisman's FIT and Cave and Wolfe's GST and the gradient model put forward by a number of authors (e.g., Andersen, 1990; LaBerge et al., 1997). We suggest that when arrays are relatively small and one-dimensional, such as those typically used in the flanker paradigm, so that neither saccades nor large shifts are required to search, visuospatial attention is diffusely focused with properties of a gradient and only the property of scaling is employed. When arrays are larger and two-dimensional, as in the present study, the need to dynamically shift, as well as to scale, the attentional focus may require the properties of an adjustable spotlight to be deployed. Finally, and particularly outside the laboratory, both eye and head movements are also used to locate targets, particularly for large fields of view.

Although the present results agree with conceptualizations that all search requires attention and is subject to top-down processes (Cave \& Wolfe, 1990; Duncan \& Humphreys, 1989; Nakayama \& Joseph, 1998), evidence from the present studies goes beyond those models by suggesting that visuospatial attention possesses two dynamic properties - shifting in space and varying in scale - that are deployed independently, depending on task demands.

\section{Effects of Adult Aging on \\ Spatial Attention and Visual Search}

Healthy adult aging appears to affect processes of search and spatial attention differentially. In feature search, the benefits of precue precision increased with age, particularly when arrays were large. In contrast, in conjunction search, the benefits of precue precision first increased from young to young-old participants (Experiments 1 and 2), but then decreased in advanced old age (Experiment 1). An even greater decrease in benefits of precue precision has been observed in aged adults in the early stage of DAT (Greenwood et al., 1997; Parasuraman et al., 1995).

We had hypothesized that the age-related slowing of conjunction search (Foster et al., 1995; Plude \& DoussardRoosevelt, 1989) could be attributed to reduced ability to adjust the attentional focus. Although we found an effect of age on the manipulation of the attentional focus, the change was not linear. An examination of Figure 4 shows, and slope analyses confirmed (Table 2), that in Experiment 1 , the effects of cue size on conjunction search first increased and then decreased as age advanced. One possible explanation for this nonlinear effect of aging is suggested by evidence that the attentional focus may be more diffuse in old people. Greenwood, Parasuraman, and Alexander (1995) found that, in the absence of location 
precues, detection of a centrally located conjunction target was slowed in the old as the number of target color distractors increased. The young were relatively unaffected by the number of target color distractors. This result indicates that, in the absence of size cues, the young are better able to maintain a target-sized attentional focus in the center of an array, whereas the attentional focus of the elderly may be more diffuse and, consequently, more vulnerable to distractor effects.

This evidence, that young individuals maintain an optimally scaled attentional focus in the absence of precues, suggests a reason why size precues are less potent for young individuals. If aging reduces the ability to adjust the scale of the attentional focus, young elderly may more closely model the size of the attentional focus to precue size, thereby obtaining greater benefits of precues. The subsequent reduction in the effects of precue size in advanced aging could be attributed to continued declines in the ability to adjust the attentional focus, even in the presence of precues. Consistent with this interpretation, search times following the largest valid cue in the oldest group in Experiment 1 approach search times reported for elderly performing search tasks without cues (Oken, Kishiyama, \& Kaye, 1994; Plude \& Doussard-Roosevelt, 1989).

Alternatively, these group differences may be due to floor effects in the young. If popout is maximally fast in the young, cue precision can have little additional benefit. To examine this possibility, we can consider data from the search task without precues. Greenwood et al. (1995) reported data from feature and conjunction search tasks in a 15-item array very similar to that used in the present study, in which mean RT for feature search was $487 \mathrm{msec}$ for young participants when the target was present. This is slower than the 392-msec value obtained in Experiment 1 for target-present trials when the cue was valid and target sized. It is also slower than the value of $447 \mathrm{msec}$ obtained in Experiment 2 with a shorter SOA for young participants. These data suggest that, compared with the uncued condition, precise location precues do speed popout. Similar comparisons between elderly groups shows that in the Greenwood et al. (1995) study without cues, RT for feature search was $626 \mathrm{msec}$, substantially slower than the 475 msec obtained after a valid, elementsized precue in the large array in Experiment 1 and also slower than the 431-msec latency under the same conditions, but with a shorter SOA, in Experiment 2. Although these data do not completely rule out a floor effect, they do show that even in the young, popout is facilitated by precise location precues. Thus, the lower limits of search speed are not reached under uncued conditions in young adults.

The power of precues to facilitate search can also be assessed by comparing the effects of valid cues on conjunction and feature searches. If precues eliminate the need for effortful narrowing of the attentional focus around the target after a valid, precise cue, conjunction search should occur as rapidly as feature search. In Experiment 1, this prediction was fulfilled in young, but not in old, participants. Although a precise cue to target size and location speeded conjunction search to the level of feature search in the young, this advantage declined progressively with age. Either older adults require more time than do the young to adjust the attentional focus to the size of the target, or some other factor continues to slow target recognition, even when target location is precisely indicated. In Experiment 2 with a shorter SOA, the effects of cue size were smaller overall, and the benefits of valid precues did not reduce conjunction search speed to that of feature search in young or old participants.

The results of the present studies partially confirm those of Plude and Doussard-Roosevelt (1989) and Foster et al. (1995), who found that aging slowed conjunction, but not feature search. Although the presence of precues in the present study does not allow direct comparisons with these previous studies, we did find that aging heightened the effects of cue size in feature search, although the overall effects of age were stronger on conjunction search. Although array-size/RT slopes were not calculated in the present studies, the interaction of age group and array size on valid trials arises from an age-related enhancement of the array-size effect, seen in both feature and conjunction search.

The effect of invalid cues also increased with age. On feature search trials, RT slowing following elementsized, as compared with column-sized, precues was greater in the elderly groups in both experiments. On conjunction search, this effect was present but did not increase with age. What did increase with age was slowed disengagement. Our previous findings, that in nonsearch cued discrimination tasks disengagement is slowed following invalid location cues in very old people (Greenwood \& Parasuraman, 1994), were consistent with the long RTs in the present work when the cue was large and located on the side of the screen opposite the target. In Experiments 1 and 2, although age did not alter the decrease in RT from the element-sized to the column-sized precues, it did heighten the increase from the column-sized to the array-sized precues, which we claim to reflect disengagement. These results confirm that the ability to dynamically adjust the attentional focus undergoes an agerelated decline.

\section{Visual Search and the Pathophysiology of Aging}

What is the mechanism by which nondemented healthy elderly begin to show reduced flexibility in control of the size of the attentional focus? All present theories of the neural mediation of visuospatial attention give a prominent role to the superior parietal cortex (LaBerge, 1990; Posner \& Petersen, 1990) on the basis of lesion studies (Posner et al., 1984), correlations with resting regional brain metabolism in DAT (Parasuraman et al., 1992), and selectively increased blood flow during conjunction but not feature search (Corbetta et al., 1995). We have recently 
summarized what is known of pathologic changes in the brains of nondemented elderly (Greenwood \& Parasuraman, 1997), and although there is evidence of declining physiology in aging, in the form of decreased blood flow and metabolism in the posterior parietal cortex, declines occur in other association cortical areas as well, such as prefrontal and superior temporal areas (Jernigan et al., 1991; Martin, Friston, Colebatch, \& Frackowiak, 1991; Raz et al., 1997). Nor do the neurofibrillary tangles pathognomonic of DAT have a selective predilection for posterior parietal areas, arising rather in limbic areas as early as the fifth decade and progressing with age from the transentorhinal region, to the entorhinal cortex, to the hippocampus (Arriagada, Marzloff, \& Hyman, 1992; H. Braak \& E. Braak, 1995), and, finally, particularly to the temporal but also to the superior parietal cortices in nondemented elderly (Arriagada et al., 1992; H. Braak, E. Braak, Bohl, \& Reintjes, 1996). Nevertheless, the existence of physiologic and pathologic changes in aging could affect the integrity of the neural networks believed to mediate visuospatial attention (Posner \& Petersen, 1990). This could underlie both the previously reported age-related slowing in disengagement of visuospatial attention (Greenwood \& Parasuraman, 1994) and the present evidence of declining ability to adjust the scale of the attentional focus.

\section{CONCLUSION}

We conclude that changes in the scale of the attentional focus are induced by location precues and that these changes develop over time at rates that depend on task difficulty. Healthy aging alters the mechanism for adjusting the size of the attentional focus. Although valid size precues can initially compensate for this impairment, further aging reduces the benefit, and eventually, attention is directed in a more diffuse manner. These findings are consistent with previous reports of age-related slowing in disengagement (Greenwood \& Parasuraman, 1994), typically the ability to redirect visuospatial attention from one side of the midline to the other following an invalid location cue in a nonsearch task. Slowed disengagement with aging might be attributed to an impaired ability to focus visuospatial attention. If the target does not appear at the cued location, attention must be shifted to find it. A large, diffuse focus could retard the ability to locate the target. If so, it would not be the shifting of visuospatial attention per se that was slowed by age but, rather, the need imposed by age of using a poorly focused "beam" to locate targets. Moreover, there may be a difference in the age at which these changes appear. Since we have here reported cue-size effects in 65-75 year olds but have previously reported disengagement effects only over age 75 (Greenwood \& Parasuraman, 1994), an increasingly diffuse focus might not give rise to disengagement effects in an empty field until the effect of aging has progressed beyond a certain point. The increased demands of search in a complex field reveal inefficiences in the deployment of visuospatial attention at an earlier point in the aging process.

\section{REFERENCES}

ANDERSEN, G. J. (1990). Focused attention in three-dimensional space. Perception \& Psychophysics, 47, 112-120.

Arriagada, P. V., Marzloff, K., \& Hyman, B. T. (1992). Distribution of Alzheimer-type pathologic changes in nondemented elderly individuals matches the pattern in Alzheimer's disease. Neurology, 42, 1681-1688.

BRAAK, H., \& BrAAK, E. (1995). Staging of Alzheimer's disease-related neurofibrillary changes. Neurobiology of Aging, 16, 271-284.

BraAk, H., BraAk, E., Bohl, J., \& Reintues, R. (1996). Age, neurofibrillary changes, $A \beta$-amyloid and the onset of Alzheimer's disease. Neurosciences Letters, 210, 87-90.

BRIAND, K. A., \& KLEIN, R. M. (1987). Is Posner's "beam" the same as Treisman's "glue"? On the relation between visual orienting and feature integration theory. Journal of Experimental Psychology: Human Perception \& Performance, 13, 228-241.

CARPenter, R. (1988). Movements of the eyes (2nd ed.). London: Pion.

Carter, J. E., Obler, L., Woodward, S., \& Albert, M. L. (1983). The effect of increasing age on the latency for saccadic eye movements. Journal of Gerontology, 38, 318-320.

CAstiello, U., \& UMILTÀ, C. (1990). Size of the attentional focus and efficiency of processing. Acta Psychologica, 73, 195-209.

CAVE, K. R., \& WolfE, J. M. (1990). Modeling the role of parallel processing in visual search. Cognitive Psychology, 22, 225-271.

Cerella, J. (1990). Aging and information-processing rate. In J. E. Birren $\&$ K. W. Schaie (Eds.), Handbook of the psychology of aging (pp. 201-221). San Diego: Academic Press.

Colegate, R. L., Hoffman, J. E., \& Eriksen, C. W. (1973). Selective encoding from multielement visual displays. Perception \& Psychophysics, 14, 217-224.

Corbetta, M., Shulman, G. L., Miezin, F. M., \& Petersen, S. E. (1995). Superior parietal cortex activation during spatial attention shifts and visual feature conjunction. Science, 270, 802-805.

Desimone, R., \& Duncan, J. (1995). Neural mechanisms of selective visual attention. Annual Review of Neuroscience, 18, 192-222.

Duncan, J., \& Humphreys, G. W. (1989). Visual search and stimulus similarity. Psychological Review, 96, 433-458.

DunCAN, J., HumphreYs, G., \& WARD, R. (1997). Competitive brain activity in visual attention. Current Opinion in Neurobiology, 7, 255261.

Egeth, H. E., Vizri, R. A., \& Garbart, H. (1984). Searching for conjunctively defined targets. Journal of Experimental Psychology: Human Perception \& Performance, 10, 32-39.

ERIKSEN, C. W., \& Collins, J. F. (1969). Temporal course of selective attention. Journal of Experimental Psychology, 80, 254-261.

ERIKSEN, C. W., \& ST. JAMES, J. D. (1986). Visual attention within and around the field of focal attention: A zoom lens model. Perception \& Psychophysics, 40, 225-240.

ERIKSEN, C. W., \& YEH, Y. (1985). Allocation of attention in the visual field. Journal of Experimental Psychology: Human Perception \& Performance, 11, 583-597.

Faust, M. E., Balota, D. A., \& DucheK, J. M. (1996, April). Interference and negative priming: Local-global attention in aging and dementia. Paper presented at the Cognitive Aging Conference, Atlanta.

Foster, J. K., Behrmann, M., \& Stuss, D. T. (1995). Aging and visual search: Generalized cognitive slowing or selective deficit in attention? Aging \& Cognition, 2, 279-299.

Greenwood, P., \& Parasuraman, R. (1991). Effects of aging on the speed and attentional cost of cognitive operations. Developmental Neuropsychology, 7, 421-434.

Greenwoon, P. M., \& Parasuraman, R. (1994). Attentional disengagement deficit in nondemented elderly over 75 years of age. Aging \& Cognition, 1, 188-202.

Greenwoon, P. M., \& Parasuraman, R. (1996, April). Control of the focus of visuospatial attention in healthy aging. Paper presented to the Cognitive Aging Society, Atlanta. 
Greenwood, P. M., \& Parasuraman, R. (1997). Attention in aging and Aizheimer's disease: Behavior and neural systems. In J. Burack \& J. Enns (Eds.), Attention, development and psychopathology (pp. 288-317). New York: Guilford.

GreEnwood, P., \& Parasuraman, R. (1998, April). Aging delays the development but increases the magnitude of effects of precue precision in visual search. Paper presented to the Cognitive Aging Society, Atlanta.

Greenwood, P. M., Parasuraman, R., \& Alexander, G. E. (1995, November). Effects of normal aging on the spatial distribution of visuospatial attention in visual search. Paper presented to the Society for Neurosciences, San Diego.

Greenwood, P. M., Parasuraman, R, \& Alexander, G. E. (1997) Controlling the focus of spatial attention during visual search: Effects of advanced aging and Alzheimer disease. Neuropsychology, 11, 3-12.

Greenwood, P. M., Parasuraman, R., \& Haxby, J. (1993). Changes in visuospatial attention over the adult lifespan. Neuropsychologia 31, 471-485.

Harpur, L. L., Scialfa, C. T., \& Thomas, D. M. (1995). Age differences in feature search as a function of exposure duration. Experimental Aging Research, 21, 1-15.

Hartley, A. A., Kieley, J., \& MCKenzie, C. R. M. (1992). Allocation of visual attention in younger and older adults. Perception \& Psychophysics, 52, 175-185.

Hartley, A. A., Kieley, J. M., \& Slabach, E. H. (1990). Age differences and similarities in the effects of cues and prompts. Journal of Experimental Psychology: Human Perception \& Performance, 16, 523-537.

Hawkins, H. L., Hillyard, S. A., Luck, S. J., Mouloua, M., DownING, C. J., \& WoODWaRD, D. P. (1990). Visual attention modulates signal detectability. Journal of Experimental Psychology, 16, 802 811.

Jernigan, T. L., ArChibald, S. L., Berhow, M. T., Sowell, E. R., FosTER, D. S., \& HeSSELINK, J. R. (1991). Cerebral structure on MRI: Part I. Localization of age-related changes. Biological Psychiatry, 29, 55-67.

JuLESZ, B. (1984). Towards an axiomatic theory of preattentive vision. In G. Edelman, M. Cowan, \& M. D. Gall (Eds.), Dynamic aspects of neocortical function (pp. 120-148). New York: Wiley.

JULESZ, B., \& BERGEN, J. R. (1983). Textons, the fundamental elements in preattentive vision and perceptions of textures. Bell Systems Technical Journal, 62, 1619-1646.

Keselman, H. J., \& Rogan, J. C. (1980). Repeated measures $F$ tests and psychophysiological research: Controlling the number of false positives. Psychophysiology, 17, 499-503.

KоCH, C., \& Ullman, S. (1985). Shifts in selective visual attention: Towards the underlying neural circuitry. Human Neurobiology, 4, 219 227.

Kramer, A. F., Martin-Emerson, R., LARISh, J. F., \& ANDERSEN, G. J. (1996). Aging and filtering by movement in visual search. Journal of Gerontology: Psychological Sciences, 51B, P201-P216.

LABERGE, D. (1990). Thalamic and cortical mechanisms of attention suggested by recent positron emission tomographic experiments. Journal of Cognitive Neuroscience, 2, 358-372.

LABERGE, D., \& BROWN, V. (1989). Theory of attentional operations in shape identification. Psychological Review, 96, 101-124.

LaBerge, D., Carlson, R. L., Williams, J. K., \& Bunney, B. G. (1997). Shifting attention in visual space: Tests of moving-spotlight models versus an activity-distribution model. Journal of Experimental Psychology: Human Perception \& Performance, 23, 1380-1392.

LuCK, S. J., \& HillyaRD, S. A. (1994). Spatial filtering during visual search: Evidence from human electrophysiology. Journal of Experimental Psychology: Human Perception \& Performance, 20, 10001014.

MAdDEN, D. J. (1992). Selective attention and visual search: Revision of an allocation model and application to age differences. Journal of Experimental Psychology: Human Perception \& Performance, 18, $821-836$
Madden, D. J., Connelly, S. L., \& Pierce, T. W. (1994). Adult age differences in shifting focussed attention. Psychology \& Aging, 9, 528538.

Martin, A. J., Friston, K. J., Colebatch, J. G., \& Frackowiak, R. S. J. (1991). Decreases in regional cerebral blood flow with normal aging. Journal of Cerebral Blood Flow \& Metabolism, 11, 684 689.

McCalley, L. T., Bouwhuis, D. G., \& Juola, J. F. (1995). Age changes in the distribution of visual attention. Journal of Gerontology, 50B, P316-P331

MülleR, H. J., \& FindLAY, J. M. (1987). Sensitivity and criterion effects in the spatial cuing of visual attention. Perception \& Psychophysics, 42, 383-399.

MüLleR, H. J., \& Findlay, J. M. (1988). The effect of visual attention on peripheral discrimination thresholds in single and multiple element displays. Acta Psychologica, 69, 129-155.

MülleR, H. J., \& RABBitT, P. M. A. (1989). Reflexive and voluntary orienting of visual attention: Time course of activation and resistance to interruption. Journal of Experimental Psychology: Human Perception \& Performance, 15, 315-330.

NakAYama, K. (1990). The iconic bottleneck and the tenuous link between early visual processing and perception. In C. Blakemore (Ed.), Vision: Coding and efficiency (pp. 411-422). Cambridge, MA: Cambridge University Press.

NAKAYAMA, K., \& JosePH, J. S. (1998). Attention, pattern recognition, and popout in visual search. In R. Parasuraman (Ed.), The attentive brain (pp. 279-298). Cambridge: MIT Press.

NaKayama, K., \& Makeben, M. (1989). Sustained and transient components of focal attention. Vision Research, 29, 1631-1647.

Nakayama, K., \& Silverman, G. H. (1986). Serial and parallel processing of visual feature conjunctions. Nature, 320, 264-265.

NisSEN, M., \& CORKıN, S. (1985). Effectiveness of attentional cueing in older and younger adults. Journal of Gerontology, 40, 185-191.

Oken, B. S., Kishiyama, S. S., \& Kaye, J. A. (1994). Age-related differences in visual search task performance: Relative stability of parallel but not serial search. Journal of Geriatric Psychiatry \& Neurology, 7, 163-168.

OKen, B. S., Kishiyama, S. S., KaYe, J. A., \& Howieson, D. B. (1994) Attention deficit in Alzheimer's disease is not simulated by an anticholinergic/antihistaminergic drug and is distinct from deficits in healthy aging. Neurology, 44, 657-662.

Parasuraman, R., Greenwood, P. M., \& Alexander, G. E. (1995). Selective impairment of spatial attention during visual search in Alzheimer's disease. Neuroreport, 6, 1861-1864.

Parasuraman, R., Greenwood, P. M., Haxby, J. V., \& Grady, C. L. (1992). Visuospatial attention in dementia of the Alzheimer type. Brain, 115, 71]-733.

Plude, D. J., \& Doussard-Roosevelt, J. A. (1989). Aging, selective attention and feature integration. Psychology \& Aging, 4, 98-105.

PoSNER, M. I. (1980). Orienting of attention. Quarterly Journal of Experimental Psychology, 32, 3-25.

PosNer, M. I., \& PETERSEN, S. E. (1990). The attention system of the human brain. Annual Review of Neuroscience, 13, 25-42.

Posner, M. I., Walker, J. A., Friderich, F. J., \& RAFal, R. D. (1984). Effects of parietal injury on covert orienting of attention. Journal of Neuroscience, 4, 1863-1874.

Previc, F. H. (1996). Attentional and oculomotor influences on visual field anistropies in visual search performance. Visual Cognition, $\mathbf{3}$, 277-301.

Previc, F. H., \& Blume, J. L. (1993). Visual search asymmetries in three-dimensional space. Vision Research, 33, 2697-2704.

Prinzmetal, W., Presti, D. E., \& Posner, M. I. (1986). Does attention affect visual feature integration? Journal of Experimental Psychology: Human Perception \& Performance, 12, 361-369.

Raz, N., Gunning, F. M., Head, D., Dupuis, J. H., McQuain, J., Briggs, S. D., LoKen, W. J., ThORNTON, A. E., \& ACKER, J. D. (1997). Selective aging of the human cerebral cortex observed in vivo: Differential vulnerability of the prefrontal gray matter. Cerebral Cortex, 7, 268-282. 
Robinson, D. L., \& Kertzman, C. (1990). Visuospatial attention: Effects of age, gender and spatial reference. Neuropsychologia, 28, 291-301.

Spieler, D. H., Balota, D. A., \& Faust, M. E. (1996). Stroop performance in younger adults, healthy older adults and individuals with senile dementia of the Alzheimer's type. Journal of Experimental Psychology: Human Perception \& Performance, 22, 461-479.

Treisman, A. M. (1985). Preattentive processing in vision. Computer Vision, Graphics \& Imaging Processing, 31, 156-177.

Treisman, A. (1988). Features and objects: The Fourteenth Bartlett Memorial Lecture. Quarterly Journal of Experimental Psychology, 40A, 201-237.

Treisman, A. (1996). The binding problem. Current Opinion in Neurobiology, 6, 171-178.

Treisman, A., \& Gelade, G. (1980). A feature-integration theory of attention. Cognitive Psychology, 12, 97-136.

Treisman, A., \& Gormican, S. (1988). Feature analysis in early vision: Evidence from search asymmetries. Psychological Review, 95, 15-48.

WECHSLER, D. (1981). Weschler adult intelligence scale-revised. NeW York: Psychological Corporation.
WINER, B. J., BRown, D. R., \& Michels, K. M. (1991). Statistical principles in experimental design (3rd ed.). New York: McGraw-Hill.

ZelinsKy, G. J., \& SheinberG, D. L. (1997). Eye movements during parallel-serial visual search. Journal of Experimental Psychology: Human Perception \& Performance, 23, 244-262.

\section{NOTE}

1. It should be noted that the young-old group had better memory scores than the young group and more years of formal education than either the young or the old-old group. With regard to memory, we frequently observe that young-old groups outperform young groups on the WMS Logical Memory subtest (Greenwood \& Parasuraman, 1991, 1994; Greenwood et al., 1993). This could be due to high levels of educational attainment, but it could also be attributed to motivation factors. Nevertheless, generalization from such a select sample should be done cautiously.

(Manuscript received October 17, 1996; revision accepted for publication May 10, 1998.) 